\title{
Hearing Ourselves Speak: Finding the Trans Sound in the Ohio River Valley
}

\author{
Gwendolyn Patricia Saporito-Emler \\ West Virginia University, rmh0053@mix.wvu.edu
}

Follow this and additional works at: https://researchrepository.wvu.edu/etd

Part of the Musicology Commons

\section{Recommended Citation}

Saporito-Emler, Gwendolyn Patricia, "Hearing Ourselves Speak: Finding the Trans Sound in the Ohio River Valley" (2021). Graduate Theses, Dissertations, and Problem Reports. 8215.

https://researchrepository.wvu.edu/etd/8215

This Thesis is protected by copyright and/or related rights. It has been brought to you by the The Research Repository @ WVU with permission from the rights-holder(s). You are free to use this Thesis in any way that is permitted by the copyright and related rights legislation that applies to your use. For other uses you must obtain permission from the rights-holder(s) directly, unless additional rights are indicated by a Creative Commons license in the record and/ or on the work itself. This Thesis has been accepted for inclusion in WVU Graduate Theses, Dissertations, and Problem Reports collection by an authorized administrator of The Research Repository @ WVU. For more information, please contact researchrepository@mail.wvu.edu. 
Graduate Theses, Dissertations, and Problem Reports

2021

Hearing Ourselves Speak: Finding the Trans Sound in the Ohio River Valley

Gwendolyn Patricia Saporito-Emler

Follow this and additional works at: https://researchrepository.wvu.edu/etd

Part of the Musicology Commons 
Hearing Ourselves Speak:

Finding the Trans Sound in the Ohio Valley Region

Gwendolyn Saporito-Emler

Thesis submitted to the

College of Creative Arts at

West Virginia University

In partial fulfillment of the requirements for the degree of
Master of Arts in
Musicology

Travis Stimeling, Ph.D., Chair

Jennifer Walker, Ph.D.

Matthew Heap, Ph.D.

Cris Mayo, Ph.D.

Department of Musicology

Morgantown, West Virginia

2021

Keywords: music, musicology, trans, queer, lgbt, culture, religion, opera, activism Copyright 2021, Gwendolyn Saporito-Emler 


\begin{abstract}
Hearing Ourselves Speak: Finding the Trans Sound in the Ohio Valley Region
\end{abstract}

\title{
Gwendolyn Saporito-Emler
}

This thesis discusses at length the experiences of four interviewees, selected for being both musicians as well as transgender people. From the author's shared perspective as a trans woman, this work addresses the issues and boons of being trans musicians. It reflects their experiences, both positive and negative, as well as provides conjectural analyses of the respondents' shared stories. It identifies common themes, issues regularly experienced by trans people, and offers arguments on why ending this hate is so vitally essential. 


\section{Contents}

Introduction. . . . . . . . . . . . . . . . . . . . . . . . . 1

Alpha Transcript. . . . . . . . . . . . . . . . . . . . . . 16

Beta Transcript. . . . . . . . . . . . . . . . . . . . . . 32

Gamma Transcript. . . . . . . . . . . . . . . . . . . . . . . • . 38

Delta Transcript. . . . . . . . . . . . . . . . . . . . . . . 59

Conclusion. . . . . . . . . . . . . . . . . . . . . . . . . . 88

Works Cited. . . . . . . . . . . . . . . . . . . . . . . . 115 


\section{Acknowledgements}

$\downarrow$ To my family, blood and found: This wouldn't exist without all of you!

$\downarrow$ To my mentors, past and present—you know you guys are in the family category too, right?

$\uparrow$ To the downtrodden, lain-low, and silenced. To Leelah Alcorn. To all my sisters, siblings, and brothers, gone before their time.

$\downarrow$ To Gabriella, the star in my sky, the coal in my furnace, my lighthouse. My heart is shaken like the pines in the wind 


\section{Introduction}

Trans narratives are neglected in contemporary musicology. Whether through the omissions of our historical contributions to the field or through the overlooking of our ongoing participation in the music of the world, trans narratives are excluded. Worse, we are often erased or argued out of textbooks, or we are told that our contributions are less than those of our cis peers-our contributions are never seen as greater than or equal to. This ethnography overturns this silencing. It will be a point of departure from which I will let my career blaze through millennia of history, reviving historical trans narratives and championing those of the present. It begins now, with a firm assertion that no longer will trans people be unheard in the lecture halls, unseen on projector screens, unread in the texts. It begins now, with an endeavor to collect narratives from rural Appalachia, a geographical region popularly viewed to be the least queer in the nation. It begins now, with this research into the lives of trans musicians, to learn their stories, and to enshrine them forever as part of the fabric of music. I cannot pretend to be impartial - I am a trans woman, but this is no more a hindrance than a conviction- living proof that I know exactly what not seeing yourself in your history does. I know the damage. Neither can I pretend that this work will shift mountains. What I do know is this: change begins somewhere, and I intend to pull that somewhere into my reality.

A quasi-glossary is necessary in order to make this work as accessible as possible,. For many of the terms, I offer my own colloquial definitions. Metronormativity is the concept that urban-ness is the standard to which all should strive. In the context of this project, it is specifically the notion that queer people are best suited for city living - it is the idea that a queer person living in a rural locale must venture to "The City" in order to complete their metamorphosis into a queer person. This also entails a rejection of rurality en masse, abandoning 
it as some kind of wasteland of bigotry and soybeans. Trans is an adjective, transgender is too. One is a transgender person, not 'a transgender'. Neither is it a verb; one does not transgender or trans. Nor is it a noun: one is not a trans. To be trans is to experience consonance with a gender expression different from that which was assigned to oneself at birth. Oftentimes this comes alongside a painful dissonance with the assigned gender called dysphoria (the antithesis of euphoria), but dysphoria is not a requisite for being trans. Many find euphoria in aspects of a gender other than their assigned which then becomes the motivator behind their identifying as trans, rather than pain in the one they were given. However, this does not mean that gender is binary. Rather, it is a spectrum of felt emotion and consonance with presentation and perception. Thus, non-binary people are individuals who experience a consonance with elements of male and female presentation, or with neither, or with some blending. In my interviews, I made a point not to delve into sexual specifics. This is intentional. Not only is such matter completely irrelevant to my work, but I also find it personally very taxing to have to endure a deluge of invasive questions.

Why am I exploring trans music making in the Ohio Valley region, specifically? Why not explore urban settings, where trans people are thought to exist more frequently? I admit a personal connection to this face of my project as well: I am from Rural Appalachia. Though I grew up in the relative hustle of an Ohio town, the aspects of mountain living were never far from hand; hill music is some of the earliest that I can recall hearing. This base of Appalachian experiences, as well as knowing the socioeconomic biases that my home faces, call me to its aid. It is no secret that Appalachia, especially the tract local to the Ohio River valley, is scarred with tales of abuse and federal neglect, possibly the worst of which comes from the lie that we are an 
ignorant, queer-hating gaggle. Queer people exist here, and we make music here, and I aim to make that apparent to any who'll listen.

While originally conceived of as a broad-strokes data collecting mission, certain global situations quickly changed the course of my work. My scope rapidly shrunk from an estimated two dozen or more to a spare handful. In its early stages, this study was meant to involve a "snowball effect" collection of respondents, so-called for its way of gathering more respondents via word of mouth (much like a telephone tree). It also would have had me going up and down the Ohio River, scouting out performance venues and listening for trans performers in their elements. Alas, as with countless theses, the COVID-19 crisis made swift work of my best laid plans. Faced with indefinitely closed venues and a complete moratorium on in-person interviews, my dreams of a proper ethnography were cast to the winds. I was undeterred, however, and this study quickly took new form, focusing instead on the testimonials of four respondents and one auto-ethnography. These four respondents and their interactions with music, then, have shaped the project. Respondent Alpha, is a non-binary person, a classically-trained soprano, and is currently pursuing a Master's degree; respondent Beta is a trans man who sings in various nonprofessional choirs; respondent Gamma is a non-binary person with a background in popular and classical music who is pursuing a Bachelor's degree in music focused on popular stylings; respondent Delta, lastly, is a non-binary person in the last year of a dual Bachelor's degree in contemporary and operatic vocal performance. I will be allowing their words, their stories, to lead the discussion, offering connective material and drawing conclusions throughout. These four musicians offer a glimpse into the world of being trans by way of their experiences and an approach to understanding and inclusion. 
I chose to work mainly with two publications: Mary Gray's Out in the Country and Glasby, Gradin, and Ryerson's Storytelling in Queer Appalachia, but there were many other works that were left out of this project, but still exist within the same tapestry as this writing. The first of these is Nadine Hubbs's The Queer Composition of America's Sound. This text is a retroflection on the queer lives and interactions of famous American composers from the early to late $20^{\text {th }}$ century, such as Aaron Copland, Leonard Bernstein, and others. This work is a conversation about past events and their current implications, which is distinct from the below project in that the interviews conducted are of active, living musicians. However, Hubbs's writing and my own exist in the same realm of queer musicology. Another such text, Lori Girshick's Transgender Voices, also exists in the present. Voices is a 2000s-contemporary survey of transgender adjacent identifying people and their social experiences. It is, overall, a collection of interview transcriptions that discuss at large the trans experience. Girshick primes the reader with an explanation of terms and theory, as well as methodology. This likely sounds familiar, as this book uses a similar format to my own project and that of Gray's Out in the Country, discussed below. Girshick even has a chapter discussing the construction of the self, a concept addressed readily by all four of my respondents. This idea of a glossary of terms at the front of the writing is echoed once again in Transgender Communication Studies, a collection of essays edited by Leland Spencer and Jamie Capuzza. This 2016 publication is, at large, a discussion of the myriad ways trans people interact with each other and with cis people via the media writ large, both with intent and consent, and without. While this book is a wonderful wealth of writing, it doesn't dedicate a chapter to musical communication, putting Studies in the same category as the aforementioned books. 
In addition to fighting the anti-rural bias plainly evident in contemporary discussion, I place my work in legacy with the scholarship of Mary Gray presented in her book Out in the Country, a discussion of queer community building in rural Tennessee and Kentucky. I draw heavily on Gray's research methods and mechanisms of interpretation, making my work tied to hers from its bones out. An in-depth look at the book's content is thus relevant to and warranted for this research.

Out in the Country acts as the cornerstone of this project in that it provides a secure footing and a framework for the research therein. In this text, author Mary Gray opens a window to the world of Appalachian queer communities, particularly those in the Smoky Mountain ranges of eastern and central Kentucky. Her polling and ethnography of young queer people in this region informs her discussion of issues facing queer youth; it also validates their existence by showing that they do indeed exist. Gray shows that queer people have always existed in Appalachia and she discusses our relationship with acceptance or lack thereof in rural spaces, the existence of more 'traditional' forms of queer community building (public organizations, awareness raising, etc.) that would be more familiar to metropolitan queer people, and the queer cooptation of new forms of media and new publics - corporate spaces, for example. Gray also discusses the impact of seeing oneself reflected in these new media, as well as the negative influences inherent within false representation. Additionally, she analyzes the metronormative representation of rural queerness via a discussion of the 2005 film Brokeback Mountain, particularly through the threat of assault and murder faced by the movie's lead characters.

Gray discusses the internal and external factors which impact these rural queer communities. She presents the idea of acceptance in a rural community as coming from familiarity. She states that "familiarity is the lingua franca of the rural", which is to say that to be 
"from around here," so to speak, is to be familiar and accepted. ${ }^{1}$ Parallel to this familiarity is the sense of being unfamiliar, foreign, or unaccepted. Queer people are thought of, by discriminating and accepting minds alike, as a people who only exist in urban spaces. As Gray attests, this is both the result of media portrayal (both well-meaning and antagonistic) and organized outreach programs. The conversation about the acceptance of queer folk in rural spaces thus "hinges not on whether LGBT youth look like everyone else as much as do they live here at all."2 Gray also discusses the decisions and behaviors of queer people on an individual level in rural spaces, pointing out both the negatives and positives of imposed silence with regards to matters of sex. To the latter, Gray states that "the imposition of silence around difference and the valuing of silence concerning sexual matters left room for rural individuals to 'choose to utilize silences or silencing' to explore their queer sense of difference". ${ }^{3}$ Gray argues that queer people have existed in rural, often unaccepting spaces through their careful navigation of the awkward silences around sex imposed by both American Christian doctrine and doctrine-influenced communities. By not stepping into the light as openly queer, queer people are able to exist in rural spaces; “...rural LGBT identity politics rely almost exclusively on public faces that look 'just like everyone else; not just to integrate into local communities, but to maintain their access to the bare necessities needed to get by". 4

Out in the Country features discussions, interviews, and conversations with people across the selected region about a range of topics that relate to queerness. One chapter discusses the impact of familiarity and family-ness in on? the rural gaze. Gray discusses this through the

\footnotetext{
${ }^{1}$ Mary L. Gray, Out in the Country: Youth, Media, and Queer Visibility in Rural America (New York: New York University Press, 2009), 37.

${ }^{2}$ Ibid., 48.

${ }^{3}$ Ibid., 38 .

${ }^{4}$ Ibid., 39.
} 
testimonials of one Mary Bird who, in an effort to find people with whom to continue her work with PFLAG (Parents, Families, and Friends of Lesbians and Gays, now shortened to PFLAG as a term instead of an acronym), joined the Kentucky Extension Homemakers Association (KEHA) to make it "her base for LGBT youth advocacy." Bird had worked with the Louisville branch of PFLAG for twenty years with three as its chapter president. She and her husband retired from their jobs in Louisville and returned to "his hometown of Leitchfield, Kentucky, for 'family and a slower pace of life,' as Mary put it". ${ }^{6}$ A drive to continue her activism and a frustration "that the negative views of a couple of loud conservative religious leaders seemed to be the only ones heard in her community" inclined Bird to pull the local KEHA branch into her work. ${ }^{7}$ Gray follows Bird's experiences trying to organize "a gay teen informational forum" with KEHA's funding. ${ }^{8}$ And organize she did. With furtive permission secured from the Association's higher-ups, she planned a panel consisting of "a doctor, a minister, a teacher, a gay youth, and some parents" for September 14th, 2002 in the county courthouse. But the event was pushed around in a number of ways. For instance, Bird relates how the forum was "booted out of the space [for the presentation] we have had for months at the Grayson County Courthouse" for no legitimate reason. ${ }^{9}$ Gray states that

The Homemakers Club story illustrates the struggle to make LGBT identities fit in rural places and how important families are to this work. Families have legitimacy as 'real locals' and the imagined progenitors carrying forward the myth of continuity and familiarity so central to rural life. Families can

\footnotetext{
${ }^{5}$ Ibid, 45 .

${ }^{6}$ Ibid, 42.

${ }^{7}$ Ibid, 46.

${ }^{8}$ Ibid, 45 .

${ }^{9}$ Ibid, 49.
} 
transform or diminish the stranger status assigned to LGBT-identifying young

people by popular media and moral crusaders hostile to their cause more than

politicians ever have or will. But familiarity can only take the politics of LGBT

visibility so far, depending deeply on the local venues available for that work. ${ }^{10}$

Gray also explores the more disorganized youth-led movements in corporate locations, particularly the experiences of those involved in impromptu drag shows in rural Kentucky. These individuals, Gray explains, co-opt and utilize corporate spaces as public environments of outness. This occurs as a direct result of the specific lack of the queer-affirmative spaces that would be expected by the metropolitan eye (e.g. gay bars, coffee shops, co-ops, etc). To this effect, Gray states that "rural young people make space for themselves through acts of occupation. They work to 'be themselves.' They do so by inhabiting corporate bodies". ${ }^{11}$ This corporate occupation takes a myriad of forms, but of note in Gray's ethnography is the then-active drag scene in Springhaven, Kentucky. Gray reveals how these environments take shape. One individual explained it best:

\footnotetext{
“'Most gay people around the county, we all go to Hardee's or the new

Backyard Burgers... and then most people all haul up together in big carloads, put on some drag, runway walk the Super Wal-mart in Springhaven and walk around for about five hours... [we] have fun with our little getaway from living in rural Kentucky". ${ }^{12}$
}

These public places of business, due no doubt in some part to the increased foot traffic such gatherings bring with them, do not deny these people access or service. As a result, they are able to exist with relative safety and ease in a way that, under normal circumstances, they would not be allotted. So, while unconventional to the metropolitan eye, such places as a McDonald's or a

\footnotetext{
${ }^{10}$ Ibid, 59.

${ }^{11}$ Ibid, 96.

${ }^{12}$ Ibid, 97.
} 
Wal-Mart can become the only places in which queer people can be out in public and can meet other like-minded people. Speaking personally, I know what great impact 24-hour stores like Wal-Mart and others have on young rural people in general; going to a store and just walking around was often the only thing of interest one could do with an evening, and the fact that one could exist there under the pretense of simply being a customer changed the space from a purely corporate storefront to an indoor space that one can be with friends without getting harassed or accused of loitering.

Gray makes a point of discussing urban understandings of rural spaces, particularly along the axis of queer people. From an urban perspective, the city is a bastion of queerness, where local government agrees with the existence and rights of queer people and reflects that in its funding expenditures. There one will find a city on the hill replete with queer-affirming spaces and the actual enforcement of anti-discrimination laws. Gay bars, queer-owned businesses, and so on make up a rich texture of queer culture in urban spaces. When presented with the image of a rural space with a complete lack of such places, the metropolitan eye sees a complete lack of queer acceptance; indeed, in many respects, it sees the lack of queerness altogether. Even if some of these spaces exist in rural locales, many of them have elements which exclude young people. For example, the presence of alcohol excludes those under the age of 21 , and a small shop or bookstore requires relatively speedy transactions and small numbers of people, as well as private ownership. In chain fast food restaurants, however, larger numbers of people are able to congregate with a considerably lower cover charge, so to speak. Additionally, the nature of franchised businesses being operated from a greater distance than a smaller business amplifies the environment of apathy. The same is true for super-stores like Wal-Mart. The map of public queerness, then, is much different from that seen in urban spaces: Gray states that "[young queer 
peoples'] position as 'youth' complicates their access to the kinds of queer citizenship projects imagined by feminist and queer scholars". ${ }^{13}$

"Queer visibility" is a phrase heard frequently in contemporary discussions of privilege. Seeing oneself reflected in the media that one consumes (or is prompted to consume) is dependent upon a number of factors, not the least of which is the societal clout that one class of people wields over another. In film, for example, producers accused of narrow-minded casting and screenwriting practices often retort back with flimsy defenses of appealing to the majority, ensuring returns on investments, and others which essentially resort to an admission of catering to cisgender heterosexual male viewers. Of course, one sees the few and far between films about queer people but, in addition to being hopelessly formulaic and usually portraitive of some kind of suffering or death, these are the exceptions which prove the rule that the film industry neglects queer narratives writ large. While I have used film in this instance as an example, this same principle is applicable to virtually every form of contemporary media in American society. Representation of queerness — queer visibility — is at the root of Storytelling in Queer Appalachia, a collection of essays edited by Hillery Glasby, Sherrie Gradin and Rachael Ryerson and published by West Virginia University in 2020. The essays therein offer perspectives of queer existence in Appalachia which are, in the eyes of the prevailing cis-het culture, subversive and different - in many ways, quare. I offer a brief summary of two of these essays, Adam Denney's "A Drowning in the Foothills" and Matthew Thomas-Reid's "A Pedagogy of the Flesh" in order to relate their work and my own project. Being seen, being accepted and loved are fundamental needs for human beings, regardless of any delineating facets of their personage. To deny the opportunity of being seen, then, is dehumanizing in the first right and destructive in

\footnotetext{
${ }^{13}$ Gray, Out in the Country, 91.
} 
the second. What one finds in these essays and in my own work is proof of what pain neglect can inflict and what powers healing? love can bring.

I remember both with fondness and aching my childhood home. Put briefly, my thenunnamed queer identity as met with dual responses - my mother's, nurturing, and my father's, a hateful rebuke. Home was a place where, in the shadows of memory, I could at once see myself learning to bake at the hips of the women of my family and feel the lash of hands and fists raised against me. This dissonance shattered my perception of home, an experience sorely borne by so many queer people in our country. Adam Denney discusses the impacts of a destruction of home both conceptually and literally in "A Drowning in the Foothills" via a metaphorical examination of the lives uprooted by the creation of Lake Cumberland in Kentucky and the stories of the people who once lived in homes now destroyed. Of these, he states that "whereas newspaper articles and government documents recorded during the time were often devoid of human emotions, the stories that the locals express, whether true or false, express a humanity that refuses to be forgotten. By the act of storytelling, these stories resist the active process of erasure and survive through the narration as they are retold". ${ }^{14}$ Denney, using Lake Cumberland as a vehicle for discussing queer destruction and erasure, muses on how the idea of home is different for queer people. He posits that queer people have a less physically and geographically rooted understanding of what home is, that instead we experience home as a feeling more so than as a building. He cites our societal abuse as the cause, stating both that "when home does not present itself as a place of harbor and refuge, we understand it differently. Home becomes transitional; it manifests between the cracks of psychic potential and real-world consequences" and that "we

\footnotetext{
${ }^{14}$ Adam Denney, "A Drowning in the Foothills," in Storytelling in Queer Appalachia Imagining and Writing the Unspeakable Other, Rachael Ryerson, Sherrie Gradin, and Hillery Glasby, eds. (Morgantown: West Virginia University Press, 2020), 62.
} 
had been denied the means to build a home for ourselves, so we crafted new tools". ${ }^{15}$ As to the taproot for the abuses faced by queer people, here specifically queer Appalachians, Denney references the notion that we are viewed as different, as strange, as quare. He talks of our learned silence, our adaptive self-shrinking and camouflage. He speaks of how queerness in Appalachia is a battle with the self to be as invisible as possible, a damnation prescribed by the hellfire of the pulpit, the malign of the Other's (queer people's) difference in the eyes of "Us." He speaks of this prescription, stating that "we are poised as antithetical to our surroundings. They cast us as unnatural and we became hardened. We began to breathe slower, shallower, with longer pauses in between. Public spaces were not made for us here. We became masters of awareness. We avoided the places that made us vulnerable: bathrooms, locker rooms, sporting events, fairs, schools, church, home, et cetera". ${ }^{16}$ The places we were told were home were decided by forces outside our control to be flooded, engulfed in a torrent, made uninhabitable. These places can hold positive memories and be the subject of fondly held stories, "[illuminating] our potential to manifest psychic bonds between person, space, and place". ${ }^{17}$ However, those given homes can be ripped from our hands and demolished, leaving us with no recourse but to either rebuild and adapt or perish — to sink or to swim. I, like many of my comrades, have found home in queerness, in warm arms and open hearts. We have been walking the road of healing away from a house full of ghosts and shadows - from stories and fable to living, breathing fact. The fact of being queer, however contested and hidden behind curtains of dismissive excuses and hushed tones, is at the core of Matthew Thomas-Reid's "A Pedagogy of the Flesh."

\footnotetext{
${ }^{15}$ Ibid, pg. 67, 69.

${ }^{16}$ Ibid, pg. 67.

${ }^{17}$ Ibid, pg. 63.
} 
"They were very close friends for fifty years" is a running joke amongst younger queer historians. It makes fun of the predilection of older historians who are discussing, say, two women whose letters and records show a plainly Sapphic relationship to state that those women were simply "best friends". The painful humor of it comes from how obstinate some scholars are that they can stare queerness dead in the eyes and call it platonic or nonsexual and to deny even the possibility of non-heterosexuality. This concept is woven into Matthew Thomas-Reid's essay “A Pedagogy of the Flesh," which discusses the concept especially present in Appalachian societies of excusing queerness [kwir] as queerness [kwar]. These differences in pronunciation, as Reid elucidates, communicate the contrasting acceptance of the two categories, stating that "Queer [kwir], in my usage — whether as a noun, adjective, or verb —is meant to be diametrically opposed to queer [kwar] through an explicit connection to marginal gender and sexual identities". ${ }^{18}$ Put plainly, [kwar] is a desexualized version of [kwir], which is to say that [kwir] people have sex or are in any way, shape, or form sexually active with a non-heteronormative partner while also presenting in a queer manner (e.g. in men, having feminine-coded interests or hobbies, think "the confirmed bachelor"). [Kwar] people present in this queer manner but are not sexually active - at least not in any publicly discernable way. This notion of queer [kwir] sex being the act that puts an otherwise [kwar] person beyond the pale of social acceptability is connected in part to biblical scripture which, as commonly cited in the Appalachian reaches, "“For the flesh lusteth against the Spirit, and the Spirit against the flesh: and these are contrary the one to the other' (Gal. 5:17). The writers of the King James Bible capitalized Spirit, while flesh is uncapitalized, suggesting the supremacy of the Spirit over the flesh". ${ }^{19}$ Reid continues,

\footnotetext{
${ }^{18}$ Ibid, pg. 74.

${ }^{19}$ Ibid, 74.
} 
stating that "my lesson was clear: I could never be defined by my flesh, the carnal embodied force that left me breathless every time I saw the deacon's son shirtless during a church volleyball game. The 'spirit' of my identity was caught up in a nonflesh performance; my queerness [kwar] was acceptable in spirit as long as it was separated from the queerness [kwir] of the flesh". ${ }^{20}$ In outlining the difference between the two "queer"s, Reid sets up the tightrope's poles, across which the queer children of Appalachia all learn to either walk across or fall from. In the body of his essay, Reid relates his experiences with two men in his family, both of whom were [kwar]. I will not relay their stories here, for to pull Reid's address of them apart into quotes would be to diminish their narrative impact. Suffice it to say that he shares them and his memory of their experiences to illuminate both the suffocating worlds they lived in and how in many ways this world yet exists for our children, young [kwir] individuals who wither and rot under the lash of belt and tongue because the powers that be do nothing to stop it. Of this, Reid charges that

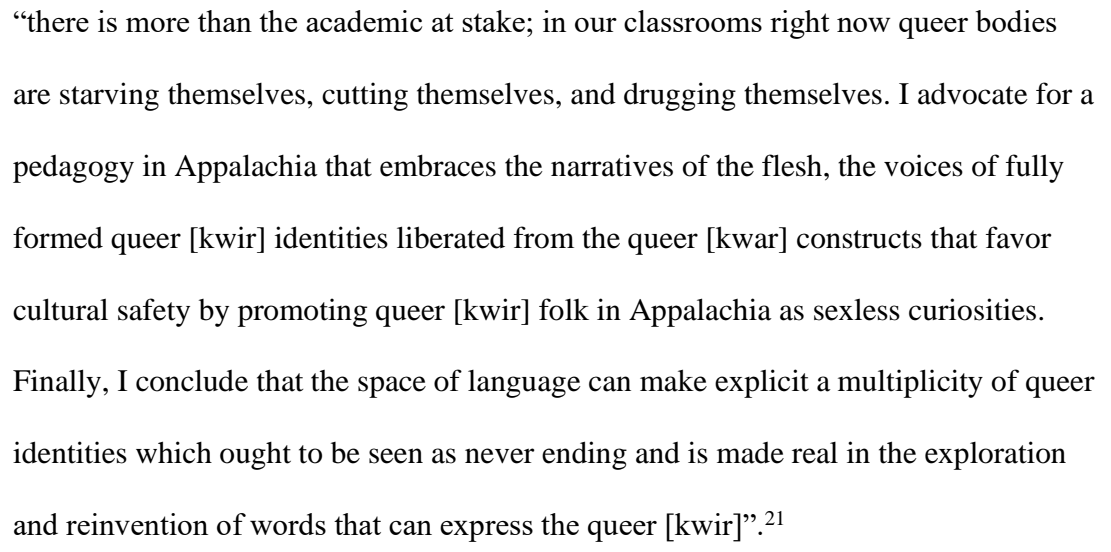

While Reid's personal experiences took place while he was in grade school in North Carolina during the 1990s, I can attest to the fact that the state of things were much the same from the

\footnotetext{
${ }^{20}$ Ibid, pg. 75.

${ }^{21}$ Ibid, pg. 76
} 
2000's to the mid 2000-teens in Appalachian Ohio. Reid talks of learning of the very real "risk of physical danger for queerness" from a game called "smear the queer." ${ }^{22}$ In my time, it was living in name and in threat, though I had not personally witnessed it.

Both of these essays communicate the damage that a lack of being seen can do to a person, as well as what love can do to right those wrongs without being able to wipe away the scars. Through these stories one can see how, without works like mine, being made invisible can unravel a trans person. I strive to be the change, to join the fight for a pedagogy of the flesh through the recognition of our queerness.

${ }^{22}$ Ibid, pg. 84. 


\section{Chapter Two: Respondent Alpha}

[Gwen]Okay this is Gwendolyn Emler the date is October 21st of 2020. This is a recording for the research project for my thesis that I'm conducting. Alpha, do I have your permission to record?

[Alpha] Yes

[Gwen] So I have a list of questions that were basically, we don't have to go down like straight this is just a conversation

[Alpha] Ok

[Gwen] Let me... Let me start with this question: What kind of music do you create and/or perform? Like how would you describe that?

[Alpha] So I'm a vocalist, I sing soprano repertoire, I sing solo music, mostly like classical repertoire. I've been doing some stuff from some opera and yeah I just kind of do solo vocal rep.

[Gwen] Yeah! I bet with, I can only assume that since COVID that ensembles are right out the window.

[Alpha] Well, I'm not in choir, like I'm not doing choir anymore because I don't have to and actually, progressing as a soloist it's not really beneficial to be in a vocal ensemble because you kind of have to stifle and blend to everybody else. So I'm not doing that. I am in an opera ensemble and we did like small scenes with like two people and we actually did get to perform that, we just didn't do it in front of an audience, we livestreamed it so it was really exciting!

[Gwen] That's cool!

[Alpha] Yeah! 
[Gwen] I should write that down, 'livestreaming of performances'. So you're still like working within ensembles of other performers, but it's not like a unison ensemble.

[Alpha] No yeah that's correct.

[Gwen] Not like a choir.

[Alpha] Right yeah. It's very small. I know we are going to be doing an opera in the spring.

[Gwen] Ooh, whatcha doin?

[Alpha] We're doing a couple small works by Jake Heggie, so that's exciting. He's a modern, uh, modern man.

[Gwen] Modern man, the modern man

[Alpha] Thoroughly modern man!

[Gwen] [laughter] Let's see here.. About when did you start playing music? Like when did you get into music?

[Alpha] Oh, well, I started doing music when I was in fifth grade when I was ten years old. I started playing clarinet in the band. I basically played clarinet until last year, my last year of undergrad. And then I started singing my sophomore year of high school when I was about fifteen I started stuff with our choir, and then I started doing solo repertoire my senior year of high school, so when I was about seventeen.

[Gwen] Cool! So, okay would you say that music had a pretty good like — would you say that music had any kind of influence on you as a child? Like as a small? 
[Alpha] Um, well I didn't grow up in a super musical family, so I didn't really get exposed to it until I started doing it myself.

[Gwen] Mhm.

[Alpha] So I mean it definitely had an impact on me socially, like I made a lot of friends through music. It taught me discipline because when I started doing music I started having to practice and stuff. And I think honestly it was a great creative outlet. I didn't really consider myself a creative person because I didn't really do art or like drawing or painting or whatever, so that was definitely a way for me to express myself.

[Gwen] Okay, with that like self-expression note, that actually gets related to the core of what my thesis is talking about.

[laughter]

[Gwen] With that creative outlet, how much do you feel like music is tied to your sense of self? Like, do you think of yourself as like "I am a musician"?

[Alpha] Yeah for sure 100\%. I don't really think I felt that way when I started doing music, I think it was just kind of I was like someone who did music, I wasn't a musician. And I don't think I really started feeling that way until my senior year of high school because I was in the band, I was in the choir, I was in a couple choirs actually and I was doing solo repertoire, and I did know that I want to do this in college, I want to pursue a career in music, I am a musician, like this is who I am.

[Gwen] So, as you got into it, it became more of a defining characteristic.

[Alpha] For sure, yeah

[Gwen] Yeah! 
[Alpha] I think a lot of people often feel that way too.

[Gwen] Yeah, like it's sort of like spins up into that, like you don't just hit the ground running

\section{[Alpha] Right}

[Gwen] Now, I feel like I know the answer to this question but like do you feel that music plays a big role in your day-to-day life?

[Alpha] Oh for sure, I organize my whole entire schedule around music and practicing and doing my classes and meeting with my therapist and voice lessons and, for sure I don't think there's a single day that I'm not doing something musical. And it hasn't been for a very long time.

[Gwen] Because I mean especially now because like you're working at a master's level, right?

[Alpha] Can you repeat that?

[Gwen] Sure! You're working at a master's level, right?

[Alpha] Yeah.

[Gwen] Something I should make note of: If at any point that you don't want to answer any of the questions, that's fine, that's absolutely fine. The cover letter speaks to that.

[Alpha] For sure, yeah, I mean yeah I wouldn't expect you to be like "answer!!"

[laughter]

[Gwen] What kind of music did you listen to growing up? 
[Alpha] Oof, um, well I listened to a lot of rock actually because my dad listened to a lot of rock and I thought it was just like, "I didn't want to be like other girls" so I listened to a lot of classic rock, and I think when I joined choir I started listening to choral music quite a lot. I also listen to quite a bit of pop music because my mom loves pop.

[Gwen] Yeah

[Alpha] You know my mom!

[Laughter]

[Gwen] So rock and pop mostly, outside of choral ensemble music.

[Alpha] Yeah.

[Gwen] Would there be any other influences or...?

[Alpha] Like the stuff I listen to?

[Gwen] Yeah.

[Alpha] I think, well in high school I started listening to a lot of indie music, so me and my friends. And if I found a new band or something I'd be like "You guys have to listen to this band!" and blah blah blah

[Laughter]

[Alpha] Pretty good spread!

[Gwen] If you don't mind, can you explain to me how you identify with regards to gender? 
[Alpha] Yeah! I identify as a non-binary person. I feel like I definitely don't fit in the category as someone who is male, but I also don't really feel like I fit in the category as someone who is female. Overall, that's how I feel. It also kind of fluctuates. For the most part I don't feel like any person really identifies all one way all the time, like I think there are days where I especially will be like "oh I feel more masculine today so I would like to bind my chest and like wear a loose fitting shirt and maybe wear boxers or something like that". Other days I'm feeling more feminine and I'm like "Oh let me wear a dress. I'm going to do my makeup", that kind of thing.

[Gwen] All sorts of stuff! Ok, thank you! Do you feel that that plays into your music and your relationship with music?

[Alpha] Yeah, it's kind of difficult just because I am a soprano, like that's my voice type, being someone who is assigned female at birth. So a lot of the roles that I portray in opera pieces are female. So sometimes that is kind of difficult because I'm like especially on a masculine day I don't want to dress female but I do end up having to just for the sake of the character. So that is a struggle sometimes, but I'm learning to come to terms with it.

[Gwen] Yeah. Do you feel like a certain distance between you and your performing self? Like is that a character that you have to don to be able to perform?

[Alpha] Oh for sure, every time I perform I'm a character. Underneath the character I am me, but I'm always a different character in every song that I sing.

[Gwen] But it's never just you?

[Alpha] Oh no, because I would like pee my pants.

[Laughter]

[Gwen] Once it's actually you, then it's like "Oh good, stage fright". 
[Alpha] Right.

[Gwen] So, assuming stage fright weren't a thing, how would you feel about performing as you, like what would you want to do?

[Alpha] What do you mean by that?

[Gwen] Like repertoire choices, like what would you pick?

[Alpha] Oh! I mean I think I personally would like to maybe sing some lower mezzo roles, or maybe some higher tenor roles. But I can't really do that right now when I'm developing my voice, and that's ok, but I think it would make me feel better in my gender to not be like... especially since I'm a high soprano I'm definitely stereotyped as the more feminine roles.

[Gwen] Yeah, and it's just so blatant, especially with the lyrics too.

[Alpha] I know it's always like "I'm in love with this man"

[Gwen] "And my womanly love of this man"23

[Alpha] Yeah, "In my bosom"

[Laughter]

[Gwen] It's all like that!

[Alpha] Really! I think more modern music not so much, but definitely the romantic period and the classical and the baroque periods as well, for sure.

\footnotetext{
${ }^{23}$ For more on gender stereotypes in opera, see Carolyn Abbate's "Opera, or the Envoicing of Women" (Published in Musicology and Difference, 1995. Or Catherine Clément's "Opera, or the Undoing of Women" (Published in 1979).
} 
[Gwen] But not so much Romantic and sort of the whole middling from 1950 backwards to 1750.

[Alpha] Yeah.

[Gwen] Now is that just because you've lived there for too long, or lived there for a lot of repertoire, or is it something else?

[Alpha] In the Romantic period?

[Gwen] Yeah

[Alpha] Yeah I have a very big expressive voice, so I do a lot of romantic rep. [Laughter]

[Gwen] Tired of it! Let me out! [Laughter]

[Alpha] I was very all about it when I first started doing it, but now I'm "lets do something else"

[Gwen] Bye!

[Laughter]

[Gwen] Do you think part of that has to do with the especially gendered quality of the lyrics?

[Alpha] Yeah I think so.

[Gwen] Yeah, because if memory serves there's a lot more, expressive of cis femininity in a lot of Romantic language.

[Alpha] Absolutely, yes. 
[Gwen] Does, and I feel like know the answer, but does music provide a sort of stress release, or is it a stressor?

[Alpha] It definitely depends. Like, obviously preparing repertoire is very stressful and getting it performance ready is very stressful but at the same time, I really don't know what I'd be doing if I wasn't doing this, so it's very comforting knowing that I am always going to be doing this.

[Gwen] So there's a comfort in the consistency

[Alpha] Yeah, and of course I'm not a psychopath, so I still listen to music for leisure.

[Laughter]

[Alpha] But I don't think I do it as often, just because it is my career. So a lot of times I find myself listening to podcasts and watching youtube videos rather than listening to music.

[Gwen] Mhmm. So in your free time, you don't really find yourself consuming music?

[Alpha] Yeah, for the most part. I mean I'll listen to a CD in a car ride or something, especially if I'm going to go on a long car ride to visit my mom who lives in the city or visit my partner who's at our undergrad school.

[Gwen] But other than that?

[Alpha] Right.

[Gwen] I mentioned before, but just to clarify, you have a bachelor's and are gaining a master's right now in music performance, right?

[Alpha] Yes, so I have my undergraduate in music education, and I am currently working on a master's in vocal performance in pedagogy. 
[Gwen] Hmm. What made you decide to go into a master's program instead of into a position as a teacher?

[Alpha] Well, I didn't see-so I student taught last semester in an elementary school, and I wouldn't hate teaching in a public school, like at a K-12 level, but I just don't think that that is ultimately where I would like to see myself. You know [REDACTED] was my vocal teacher in my undergrad and [they were] a huge influence on me, and I definitely would like to see myself doing something along the lines of teaching collegiate voice lessons, teaching collegiate vocal pedagogy and diction classes. That is really where I see myself, I think, in the end.

[Gwen] Goals!

[Alpha] Yeah, \#Goals

[Gwen] Do the kids still do the hashtag?

[Alpha] They'll call sharp signs hashtags.

[Gwen] No they won't!

[Alpha] No they fully will.

[Laughter]

[Gwen[ Do you write or compose ever?

[Alpha] No, not really [laughter] I mean I had to for my undergrad for some classes, and it wasn't terrible, I didn't hate it or anything, but I am a performer [laughter] I'm not a composer.

[Gwen] Yeah, performance over composition. 
[Alpha] Yeah.

[Gwen] But still, I mean, with performing, that is still an act of creation.

[Alpha] Yeah for sure I mean I definitely really enjoy interpreting pieces and watching different performances and taking different things that I like from each performance and then ultimately, I think one thing that I really like about music as a whole is that no two performances are ever the same, even if it's the same performer.

[Gwen] Do you feel, as a performer, that your gender expression ties into how you perform things?

[Alpha] Yeah I think it's also just being comfortable in who I am, and it's added to my level of confidence. Like I remember when I first started performing at the beginning of my undergrad, I was so insecure, I just didn't feel comfortable with who I was, and it affected my posture, it affected the tension in my neck and jaw and everything.

[Gwen] You get all squeezed up

[Alpha] For sure, and in becoming who I am and becoming more comfortable in myself and identifying with who I am, I've become much more comfortable performing and obviously there's less tension and all that good stuff.

[Gwen] Comfort in gender, comfort in performance

[Alpha] Yeah. And it's nice because I felt like when I was in undergrad I always felt like I had to wear a dress or a top and a skirt to perform, because that was 'fancy', but now that I'm more comfortable in my gender expression, I'll wear a men's dress shirt and khakis because that's just what I want to wear that day.

[Gwen] Lack of discrimination on that point, then. Do you experience much in the way of gender expression-based discrimination? 
[Alpha] No not really, not at my current school, not at my undergrad one either, it was just at my undergrad school it was kind of hard since I came out my last semester while I was student teaching so I wasn't really there, and I changed my name kind of quickly and so people would like deadname me, not on purpose, just out of habit, and here it was really nice because I got to introduce myself to everybody as [REDACTED], not as my deadname. Which is cool because no one ever really calls me by my deadname. I mean, sometimes I get misgendered but people are pretty good about correcting themselves, so that's nice.

[Gwen] That is nice!

[Alpha] It is! For a lot of the other people in my master's degree-first of all, all the other people in the vocal master's program, they're all women, which is nice. It's very comforting. I'm pretty much the only nonbinary person that they've all ever met before, so they'll ask me questionsthey're never rude about it either. It was really funny, one of them noticed that I cut the slit in my eyebrow and they were like "Can I call you queen, like can I say yaas queen to you?" and I was like "yeah that's fine" [laughter]

[Gwen] That's nice.

[Alpha] Yeah. Another one I remember at the end of our dress rehearsal for our opera scenes, she was like "oh good job ladies" and she came over to me and she said "I'm so sorry, I didn't mean to misgender you or anything" and I was like "no it's fine, I know that you didn't mean it, thank you for apologizing"

[Gwen] That's nice though, like that actual concern and care

[Alpha] For sure.

[Gwen] Because I mean I can only imagine that that has such a positive impact on how you're actually able to perform. 
[Alpha] Yes absolutely, I feel so comfortable. And even though we're doing it all virtually, it's still comforting.

[Gwen]That's good, I'm really glad to hear that.

[Alpha] I'm like, so happy here, it's ridiculous

[Gwen] I know, cause like you were picking between here and there and I don't even know the performance people here, I can only imagine... but I'm really glad you found a really positive community there, that's wonderful!

[Alpha] Thanks! Yay!

[Laughter]

[Gwen] I, for the most part, feel like we've gone over most the aspects that I wanted to talk about. But I do want to see if there's anything else that you want to say with respect to existing as a trans person in musical spaces?

[Alpha] Could you repeat that? You cut out for a bit.

[Gwen] I wonder if you could speak to what it's like to be a non-binary person in music spaces? Especially in music spaces that are historically angled toward cis people?

[Alpha] Yeah it's definitely - I feel out of place sometimes, for sure, but I mean like I said, everybody makes me feel very welcome and makes me feel very comfortable in my identity. They're pretty good about being like "oh if I mess up your name or mess up your gender just like let me know and I'll correct myself' and it's not a big deal. I feel like there was something else I was going to say... oh, whatever

[Laughter] 
[Gwen] So it's moreso that it is the community of people rather than...

[Alpha] For sure, and I'm a little nervous because I am thinking about possibly going and trying to perform at some point, hopefully, in like operas and maybe go with some opera company. I am a little nervous because I know that every company is different, and everyone has different directors and different staff, and so we've talked about-I'm in a vocal coaching class where we basically just discuss what it's like to audition, and what it's like to be in an opera production and blah blah blah, and we've talked about "oh should we put pronouns in our resumes" and stuff, and I still don't know, because something about being non-binary is if I don't like physically transition in any way, it's pretty easy to hide.

[Gwen] Yeah.

[Alpha] So it's not something that I have to come out and say if I don't want to, but it is important to me and it is who I am and it is my identity, so if I can I would like to.

[Gwen] Of course, yeah, but if it's going to cost you a career...

[Alpha] Exactly. And I also think that it's still very new in the sense that we don't know very many trans and non-binary people in the music world today, I mean I think it's becoming more common as people feel more comfortable coming out.

[Gwen] Yeah, and there are more laws put in place to protect us.

[Laughter]

[Gwen] Fingers crossed that it'll keep going up for us

[Alpha] Yeah really. 
[Gwen] [unrelated]...If you could put yourself in [the shoes of a trans person in an opera production]

[Alpha] Obviously I'll be playing cis women in any production that I'm in, that's just how it has to be. If it were up to me I would probably pick more gender neutral costumes to wear, I would also like to wear my own hair, maybe not every time, but I know that wigs are a huge thing in opera. One of my professors even said that she has maybe worn her own hair once out of all the operas that she's been in. So wigs are a huge thing. But I don't know, I think it just really depends on people that are in the production, and the director, and what they're willing to do with it. I know we talked in my vocal coaching class about how some directors will be ok if you have your own takes on the costume, because we were also talking about how someone got cast in a role as a white person, and it was like a witch, and they wanted to put them in dreads, and they were like "no, I don't want to do that" but they were really nervous to say anything because they didn't want to seem difficult or anything as a performer, but I think she ended up saying something and they ended up putting her in a different wig.

[Gwen] To that, and stop me if we're beating around the same bush, but do you feel that there's a pressure on you to conform into these more cis-aligning roles?

[Alpha] Yes and no, I mean it hasn't really come up for me personally yet, but there is another girl that is in my program who, she identifies as a lesbian, and she wants - she has pretty long hair right now but she wants to cut it short, but I know her teacher was like "um, it makes you more sellable if you have this long hair, blah blah blah" which, again, one of my professors even said we get put in wigs most of the time, so like why does it even matter?

[Gwen] Yeah. So from that perspective there are restrictions in some ways of actual physical presentation.

[Alpha] Yes, but I also think, as we move forward in time I think it's getting to be a bit more free. Because we just did a master class with a singer, [REDACTED], and she is an openly 
queer woman. We were on Zoom with her and she has short hair, probably about my length. She had the side of her head shaved, and she had her nose pierced and all this stuff.

[Gwen] So sort of stereotypically antithetical to the whole 'nice lady' look

[Alpha] Yeah, for sure, but I also think it depends on your voice type because she is a mezzo, so I think sometimes mezzos, there's a saying that "mezzos get cast as bitches, britches, and witches"

[Gwen] Oh right because pants roles.

[Alpha] Exactly, only mezzos really get pants roles, you don't see sopranos in those roles.

[Pause]

[Gwen] Let me go ahead and conclude this: so the time is now 5:43 and this is the conclusion of this interview.

[Alpha] Bye! 


\section{Chapter Three: Respondent Beta}

[Beta] Hello, it's Beta

[Gwen] Hi! Thanks again for participating in this study

[Beta] Yeah of course

[Gwen] So! I should inform you of a few things: this chat record will be transcribed into a text document (with your permission of course)

[Beta] You have my full permission :)

[Gwen] All identifying information will be stripped from the record, and since this is over text I'll delete the chat record once it's been transcribed.

[Gwen] Wonderful! Thank you :) A few other things: if there are any questions you don't feel comfortable answering, that's perfectly fine! You don't have to :) Also, I will be sending you a document containing several free mental health resources specializing in LGBT-centered care.

[Beta] Alrighty. Okay, Awesome !

[Gwen] Yeah! So, shall we begin?

[Beta] Yes!

[Gwen] Cool! So, just for my own sake: Time start, 11:02, record 001002102220. Beta, do I have your permission to record? 
[Beta] Yes.

[Gwen] Awesome :) ok! So can you tell me about what kind of music you perform, or create?

[Beta] I sing! I sing mainly gospel/showtunes and I perform at church.

[Gwen] Nice! And are you in any ensembles aside from, I assume your church choir?

[Beta] No, I am not. I'm only in church choir.

[Gwen] Ah, ok! How long have you been with them?

[Beta] About 8 years!

[Gwen] Oh cool! So you really enjoy your time with them then?

[Beta] Yes, I do. Music is how I express myself, and they're a great group of people, so I really enjoy it!

[Gwen] That's great to hear, having a good ensemble of good people really can make a difference. Do you feel that this ensemble has played into your life? Like have they had a big impact?

[Beta] Yeah for sure! They've allowed me a safe space to be myself and perform my music while also supporting me in finding my singing voice and teaching me how to use it properly.

[Gwen] Oh wow! So really not just an ensemble, but mentoring in a lot of ways. Would you say that they've been accepting, then? 
[Beta] Yes for sure! When my voice first started to change, I went from soprano to baritone. And I was super scared that they wouldn't accept me seeing as they're a church choir. But, the head of the choir is an older gay man who was a music major back in the day, so he took me under his wing and taught me how to sing again. And the choir members happily let me join the baritone section and have been very accepting of me as a musician and as a transgender individual.

[Gwen] Oh that's wonderful! I'm really happy for you, gosh that's nice. I can only imagine your anxiety though, before they made it clear that they were loving.

[Beta] Thank you. It's been a great experience. And yes it was very anxiety inducing. I actually was so worried about them not accepting me that I quit choir for a while. Quit going to church. But then my pastor reached out, who is a lesbian, and she wanted me to give a sermon on being transgender and such for the whole church to get a better understanding of who I am (Most people in my church are between the ages of 50-90 so they aren't really familiar with transgender) so I did. And I had so many older people correcting themselves on my pronouns and offering me comfort and their support. It was great.

[Gwen] Oh my gosh that's!!! goodness that's fantastic. It sounds like your church's leadership is lgbt-identifying, can you speak to that and how that's made you feel?

[Beta] Well, it's always a scary thing being lgbt and growing up religious. Because it seems like the vast majority of churches aren't accepting. But, since I was younger, I've known lgbt people to attend our church since I was probably like 7 years old. And my church has always been accepting of them. When I came out, it was so scary but I got welcomed with nothing but love and support from all areas of the church which helped me a lot. I'm very heavy in my faith, mainly using music to express my spirituality, so to have a place that supports who I am while doing what I love makes me feel amazing! It was actually after delivering that sermon that our church's music director approached me and told me I inspired him to be out about his own sexuality at church and the next week he brought his husband! Shortly after that is when he took me under his wing and helped me with my changing singing voice.

[Gwen] Goodness I'm so happy for you! So you've seen and met and known people in the lgbt community basically your whole life, then. You said you've been singing with that choir for about 8 years, but I assume you've been listening to that choir basically since you started attending, right? 
[Beta] Yes I have! I've attended this church since I was a baby so I've grown up listening to them sing. I used to sing with them occasionally before I transitioned as well but they were only solos for sopranos

[Gwen] So you've been publically performing most of your life, huh? At least in some capacity.

[Beta] Yes! I was in show choir from $5^{\text {th }}$ grade until junior year of high school And I was in band from $6^{\text {th }}$ grade until junior year. I played trombone in both band and jazz band, which I was in jazz band from $7^{\text {th }}$ grade until $10^{\text {th }}$ grade. And then I was in marching band from freshman year up until junior year where I played keyboard.

[Gwen] Nice! Can I ask why you stopped in your junior year?

[Beta] I transferred to a technical school which was specializing in the arts! I ended up doing their visual arts program instead of music for the rest of my high school years.

[Gwen] Oh cool! Do you prefer one to the other?

[Beta] I prefer music!

[Gwen] I figured. Are you a music major at your college?

[Beta] No I am not. I am a history major!

[Gwen] Oh shoot I knew that. Well neat! I do want to ask- could you tell me how you identify, with respect to your gender?

[Beta] Yes of course! I identify as male. I was assigned female at birth, but I identify as male and my pronouns are he/him/his 
[Gwen] Cool :) So, do you feel that your gender impacts your relationship with music? I know you talked about changing voice categorizations, but I'm thinking more like how the two intersect introspectively.

[Beta] Hmm. Well, I'd say it does. In certain way. For example, before I realized who I was, my music I'd perform would be really sad because I was sad. However, now that I know my gender and am proud, my music is much more soulful and confident and happy. Hopefully that answers your questions

[Gwen] Absolutely! Oh, I should note: I know we're over the hour, and if you want to stop for now and re-meet, that's ok! So in a lot of ways music reflects how you feel the. Would you say it's a stress relief, too?

[Beta] I'm perfectly fine continuing if you are :) And yes! Whenever I'm stressed or even depressed or anything, I sing to feel better, or I listen to music

[Gwen] For sure! What kind of music do you listen to?

[Beta] I listen to all sorts of things. I love alternative pop and alternative rock. Classic rock. Glam rock. Especially stuff from the 70's! I also enjoy classical piano music

[Gwen] Nice! Me too, except I'm more into the 80 s than the 70 s :) Do you compose any?

[Beta] I've only composed once, in marching band I had to write one of my pieces because there wasn't a keyboard part for our fourth number lol

[Gwen] So not like a habitual thing then, I see :) Cool! So, I actually don't have any other questions for you! Is there anything that you wanted to say before we wrap up?

[Beta] Nope! I think we've covered it all 
[Gwen] Ok! Thanks again for participating in this study, I really appreciate it! Oh, one last thing: with your permission, can I maintain this transcript until such time that I can place it into an appropriate archive?

[Beta] Yeah of course

[Gwen] Cool! Thank you :) Alright, so this concludes our recording of 001002102220 at $12: 36 \mathrm{pm}$. 


\section{Chapter Four: Respondent Gamma}

[Gwen] Okay, this is Gwendolyn Emler, the date is October $22^{\text {nd }}$ of 2020 . I am speaking to Gamma. Do I have your permission to record?

[Gamma] Yes, you do!

[Gwen] Neato! Oh, the time is 3:08pm. Alright, Hi!

[Gamma] Well hello there!

[Gwen] Let's start... where else better but to start at the beginning. When did you start playing music?

[Gamma] Everyone in my family started learning piano as soon as we could read. And I think that my first performance was maybe when I was six or seven in church.

[Gwen] Okay, nice! So baby, tiny

[Gamma] We were all baby-tiny-small

[Laughter]

[Gwen] So you say it was in church, can you.. so religious music kind of plays more of a larger role in fundamental experiences in music?

[Gamma] Yeah I would say that the performance of music in a religious context, but music that isn't itself overtly religious. Since it was our Nana who was a classical musician it was a lot of 
classical music, like teeny tiny reductions of melodies from symphonies that we would play in church for all the old people to enjoy.

[Gwen] But that was just- it was just that the church was the performance venue?

[Gamma] Totally.

[Gwen] Mhmm. And when you got into grade school, or when you got older rather, did you get into any music programs?

[Gamma] Yeah! From sixth grade all the way through high school I did band and choir. In band I played the alto saxophone and then in high school the oboe. I have been stuck on the melody in choir my whole life.

[Gwen] Hooked on a feeling!

[Laughter]

[Gwen] I know that you're studying music performance now? And that would be vocal performance, right?

[Gamma] Yes

[Gwen] Okay. Would you say that music has had a pretty important impact on your life, then?

[Gamma] Yeah, absolutely. Choosing music as my life's work, my small little life's work, was not an easy decision. I was drawn to a lot of different fields mostly in the arts, in the performing arts, but also all over the map. But ultimately, music was the thing that I felt had been the most consistent and the most sturdy. And even though I played other instruments and loved other instruments, no joke I chose voice because I knew it would be the easiest. 
[Laughter]

[Gwen] So you feel a big kinship with singing, with vocal performance?

[Gamma] Yeah, it wasn't easy as it turns out, it's like way harder! Everybody else you just press a button and the note happens but me I gotta do that!

[Gwen] There's no buttons on the neck place!

[Laughter]

[Gamma] Singing, it was like, y'know, not to get too intersectional on you but being a fat person you need a lot of redeeming qualities. And some of the biggest representation that fat people get is as characters in the Disney Channel Original Movie who are quiet for the first three-quarters of the movie and then at the end they sing a big solo.

[Gwen] The DCOM Gambit.

[Gamma] The DCOM Model, yeah. So it was a thing where I was like "well I have to do something", I felt like there was a lot of negative attention drawn towards me and I wanted something that would bring positive attention towards me. And I thought singing was a good way to do that, because people always liked someone who could sing. I got older and that wasn't true, either.

[Laughter]

[Gwen] Life ain't no DCOM!

[Gamma] That in itself is a Disney song, Life Ain't No DCOM 
[Laughter]

[Gwen] So with that, would you feel that music was a way of you having a social interaction with some people?

[Gamma] Yeah! We did, you know this but this is for the record, I was homeschooled growing up and our mom put us in the public school band and choir programs because we were all kind of musically inclined from that whole "playing piano since birth" thing, and we needed to meet people our age. So I didn't quite know how to interact with people. It also could have something to do with a million things, being queer, having ADHD, not understanding yourself, looking different from other people around you, but ultimately people didn't get me and I didn't get them, and the only way that I knew how to communicate with my peers was with music. You know, it's impossible for me to ask you how your day is going, but I can ask an upperclassman how to finger a D\# on my alto saxophone, and that was always a universal language, to be cheesy about it. That was the easiest way for me to interact with people.

[Gwen] Yeah! So ensembles were a really big interaction point, suffice to say?

[Gamma] It was- yeah, it was always ensemble stuff.

[Gwen] Make a lot of friends that way?

[Gamma] Well, no, but I made every friend that I had that way

[Laughter]

[Gwen] Well, how about now in college?

[Gamma] Yeah, I met all of my friends in the music department in college, and then the friends who aren't in the music department I met through other music department people. It was.. I got 
to be in the chamber choir my freshman, I was the only freshman in ye olde concentus vocum and that kind of put me in with the social big boys right off the bat.

[Gwen] Social big boys [laughter]

[Gamma] The social big boys of the music department, of my university's music department. A lot of the jazz cats were in the concentus vocum, because they understand harmony and stuff. So being in that ensemble and also in the marching band here was how I met everyone I know. Eventually it led me to the jazz program for like half a second before it fell apart.

[Gwen] That's a big oof

[Gamma] You can just end that sentence at "...led me to the jazz program” you don't have to include my issues, that's on me.

[laughter]

[Gwen] What kind of music did you listen to growing up?

[Gamma] That's a big question.

[Gwen] Big question, big answer, big money no whammies!

[Laughter]

[Gamma] Growing up it was a lot of whatever my siblings were listening to. My parents were strict around music, they were strict around the language that music used like whether that be bad words, or language that seemed sexual or even romantic most of the time, we weren't allowed to engage with. So we sort of unionized our music listening because our parents would have to proofread the lyrics to every song we wanted to listen to, cause those were in the days 
when you bought individual songs on itunes, not full albums, not streaming, it was that weird inbetween phase. So they would screen them beforehand, have a listen to them, and then let us listen to them if we decided to. So it was things from Disney Channel movies, like High School Musical, Camp Rock soundtracks, and the musical theater that my parents listened to, also the classic rock bands my parents listened to. Doesn't matter if there's sexual content in those because mom and dad like it.

[Gwen] Hypocrisy!

[Gamma] And also all four of us started taking dance lessons at some point, so we were listening to a lot of the top 40 stuff that we were dancing to, which was my mom's one exception to the screening rule. Then that quickly deteriorated into the pop/punk quadfecta through middle school, which I think was a cornerstone for a lot of queer youth, was that good Emo Phase. I was also, from the ages of 12 to about 15, really (and this is so queer coded) I was really obsessed with music that nobody else had heard of, and in my small town that's not hard to achieve, because even then nobody had heard of Fall Out Boy, but I wanted to go deeper than that, I wanted to go a level, two levels removed from music anybody had heard of.

[Gwen] 100 Gecks.

[Gamma] 100 Gecks! In 2010!

[Laughter]

[Gamma] So I listened to youtube singer/songwriters, which is where I found my own path in music when I started learning to accompany myself and sing and write music. While also listening to bands like BrightEyes and Fun. You know everybody knew those two songs but I had the whole Some Nights record, and I was obsessed with it, it was so weird sounding. And I knew that nobody else would like it except me. I also used to love Pentatonix which nobody knew about at that time either. Things that are cringe to say now, but were super cool then.

[Gwen] Airquotes around cringe. 
[Gamma] And also airquotes around super cool because everyone thought I was lame, like I thought I was the coolest guy around but everybody else was like "I've never heard of that, what is that, you're weird." But definitely, there're so many moments in my life that make me say "how did I not know I was queer" and one of them was my obsession with having different music taste than everyone else when I was younger.

[Gwen] Can you speak more to that, actually? Like how you feel like that ties into queer identity, like music choices, like what you listen to?

[Gamma] Yeah totally. So I think that- So I'm taking a queer media class right now, we're focusing mostly on film, and we started the semester with a baseline understanding of what queer coding means. A lot of it is characters who feel inexplicably different, they maybe have some big secret that they could never share with the world, they feel like they don't quite gel with other people around them, which was always my experience that I've attributed to about a hundred thousand different things in my life.

[laughter]

[Gamma] But I think a big essential one is queerness, and I think that my queerness in part led to me not fitting in with people my age, and an extension of that was setting myself apart by listening to different music or watching different shows or reading different things. I think it was all- I don't even think it was necessarily performative, because I don't think that I cared enough about what other people thought of me to perform for them. I think that it was really just- I wanted to find things that were unique and I wanted to be an individual.

[Gwen] You found kinship in that difference.

[Gamma] Yeah, totally, I think that that all important sense of individuality is pretty central to being a queer person, where you feel misunderstood and like nothing can possibly get you.

[Gwen] Yeah, but finding that thing that's also on the fringe. Now, to that, could I ask you to talk about your identity, like vis-à-vis your gender? 
[Gamma] Yeah it's a big question mark. My gender is bucket. I use they/them pronouns and I go by [REDACTED] which is a nickname for my middle name.

[Gwen] So removed from the removed.

[Gamma] Yeah. So I changed my name when I graduated high school, another thing- should've known I wasn't cis when I said "I can't describe it but my first name doesn't fit me" and never questioned it beyond that.

[laughter]

[Gamma] When I used to perform music in high school, I used to gig and I used to- from the ages of 15 to 17, there was this little coffee shop in downtown Clarksburg where a bunch of the cooler punk/rock kids would go to play music and I would go with my ukulele and I would sing stuff, and all of the music I chose was really sad because I was really sad. My dad used to make fun of me for always picking really sad music, but I always introduced myself as a different name. It wasn't always my middle name (it often was), but I would just pick different names to introduce myself as. Like I was playing a character, I was trying things on, and because I knew it would physically hurt me to introduce myself as my first name. I asked people not to use it as much as possible, and to just try to refer to me by pointing. So I graduated high school and decided I wasn't going to go by my first name anymore. Backlash from my parents immediately, but I was pretty comfortable in early college going by [REDACTED]. I ran into this guy who was my drum major in marching band, which is the first place I went, and we used to know each other in middle school. He said "hey [deadname]" and I went "oh I don't go by that anymore I go by [REDACTED] now." And he goes “oh alright, I'm going to introduce you to my friends" and walks me over to his friends and says "hey this is [REDACTED]".

[laughter]

[Gamma] I had not intended to nickname myself, I was trying to just be [REDACTED] and I was thinking "even if I went by a nickname I was thinking more [REDACTED]" I was just "ok I guess I'm [REDACTED] now". Which is wild because it's a name that makes so much sense to me, but I didn't choose it, It's like it found me. I think in a lot of ways my gender found me too. I was obsessed with hyperfemininity when I was younger. I have a makeup artistry degree. I took an online course my junior year of high school, got a degree, and then just need to go somewhere and get a certification if I ever want to work, but I don't. But I loved dresses and pink from the time I was a little baby, and you know skipping the emo phase, that was pretty much my whole thing, and I didn't have the personality for it, I wasn't particularly bubbly. I was awkward and funny sometimes and loud, but appearance-wise I felt like there was a lot to 
compensate for. I think I was mostly thinking about my body when I was younger, but I realize now that I was compensating for a lot of things.

[Gwen] And it just manifested.

[Gamma] Mhmm, and was like "if I can look as feminine as possible, then I can compete", so to speak, "with the ugliest thin woman here". It was all about getting to a point where people would listen to what I had to say or people would see me and recognize me and know who I was, know that I was 'girl' by looking at me. I thought people couldn't tell what my gender was if I wasn't wearing a dress and makeup and had long hair. Then, in my junior and senior year, I started identifying as a lesbian. I cut my hair really short, I still wore a lot of dress and makeup, but I thought that me cutting my hair short was really liberating. Having an identifier like that at such a young age is really powerful. It added this new aspect to my character, where I was able to be like "yes I am lesbian, that is me". And that's not me, that's who I thought I was at the time and I think that's valid.

[Gwen] It is!

[Gamma] Then, going into college and saying "no, I'm not a lesbian, I am not The Lesbian, I am The Bisexual" and then going from that to "I am The Non-Binary" was sort of this weird selfdiscovery that I'm still on, and I don't think I'll ever be off.

[Gwen] For sure, yeah.

[Gamma] But it's definitely been a pretty big indicator of where I am, emotionally, and I've gone through so many stages with femininity and with masculinity and with my sexual and with my gender that it feels wild that I'm still going, that I'm still learning shit about myself. It feels wild to think about like "what if I have to pick a third name". It's like I had first name, nickname for first name, middle name, nickname for middle name, new name? Like how many are we at now! Five? Do I need five? I don't think I do!

[Gwen] A dragon's hoard of name! 
[Laughter]

[Gamma] But I didn't have much trouble at all as far as peers were concerned in college coming out. It was simple people just made the switch, and if they slipped up they would apologize and move on. There were a few people who were resistant to it and those who were still are, even though I came out a little over a year ago. I had difficulty with professors, with music faculty, if you want me to get into that in a follow-up question, but really, coming out to my peers was no problem. Which I'm very fortunate for because that's not the case for everybody. Especially not at a Methodist college in rural West Virginia. You wouldn't think, huh?

[Laughter]

[Gwen] Yeah actually, would you mind speaking to that, moreso to how did discrimination make you feel in ensemble performances?

[Gamma] Yeah so a big thing: my sophomore year we went to ACDA, which is the American Choral Directors Association, conference, which is where they do a big honors collegiate choir, and one year the whole chamber choir from [UNIVERSITY] went, and while we were there, our choir director sat in on this lecture about inclusivity in choir, about specifically gender variance in choir. I remember he came back to us with this big inspired speech about how he was going to change his dress code policies and the language he used to refer to voice parts and things like that. And then he never did. So it was still, when I went back to choir, I was still expected to wear a floor-length dress with $3 / 4$ " sleeves or longer, all the things you have to adhere to in concert black. When he was talking about having a third option or getting rid of the options altogether and saying "Wear black, make sure it covers these parts so that we look uniform". But nothing changed and he stayed very binary, you wear a suit or you wear a dress, you perform femininity or you perform masculinity. He never bothered to change the language around referring to voice parts, which I think is huge for a lot of ensemble musicians. It's like when you're talking to tenors and basses and say "guys", that's not true, that's not the full truth.

[Gwen] No, it's not. 
[Gamma] I mean, just last week I sang a women's Sunday service at the church that I work for, and it was the whole big thing was that it was just the women singing this week in the choir. And I love the choir director of that church, that's a different person from the choir director from my school whom I don't like, but the director at the church is incredible and she's a queer woman and she had corrected herself eight million times and gendered my correctly 8 million times, and I know that she just wanted someone to sing the goddamn melody and that's why she brought me in, but it was like, you know, to be singing hymns all about the virtues of women and about sitting in on a sermon on the experience of women and just having this weird "girl-power" event where I'm not a girl.

[Gwen] Yeah, where it's not discussing you.

[Gamma] Yeah, in a musical setting too, where you're singing and it's vulnerable and personal, so to be really involved in something that doesn't make sense for you, something that doesn't apply to you was really weird, in a way I didn't anticipate it being. I also pushed back- I'm sorry I keep jumping back and forth.

[Gwen] No, it's ok.

[Gamma] With the school's choir director, the one who didn't change the language or the dress code or anything, he also... he and I... I pushed back against it incredibly hard especially because I didn't want to out myself to him, but I pushed back against it and I said "Hey you said you were gonna do all these things, and if you're not then I'm not going to do choir next semester, and I'm going to take a semester off from it and see if you've changed your mind when I come back. And that semester was hell because of that professor. He was the head of our department at that point, he docked my jury score and cited that I hadn't been active in the department, even though I was in every ensemble that wasn't choir and you could've checked my grades, I had A's in every music course I was taking.

[Gwen] So he just out and out went out of his was to cause you harm?

[Gamma] To fuck me over. And what he did was I was half a point away from making the score I needed in order to do a recital so that I could graduate with a music degree. And he kept me at that half a point away, essentially saying "You're either staying another semester or you're doing 
an extra jury because I don't like you, because I don't like you questioning my teaching methods. So that same semester dropped my music major and because a music minor, because it wasn't worth it at all. It's not like- and I know that he would've been way more sympathetic to the shit I had to say if I said "hey I'm nonbinary, the reason I want you choir to be more inclusive is for me" I think he would've been more sensitive to that, but I shouldn't have to fucking do that, I shouldn't have to beg a choir director to let me wear what I want to a performance. And I shouldn't have to bring up my transcript to get a jury score reflective of the amount of work I've put in.

[Gwen] No.

[Gamma] And I don't think that... I think that was discrimination against me, I don't think that was discrimination because of any of my identifiers, I don't think that was because I'm queer, necessarily, I don't think it's because I'm fat or because I am a woman as far as most people are concerned; I think it was just that he didn't like me, he didn't like me questioning things, didn't like me pushing back on authority, which is queer- it's the pushing back against authority and fighting for new ways of thinking that envelope and encompass all people, is like the cornerstone of every queer movement that's ever happened. So I think it was less that he was angry that I was queer and more angry that I was trying to create more space for queer people.

[Gwen] Yeah! Hmm, and you feel that, had you been out to him- had you basically outed yourself to him, he would have agreed? Or he would have conceded?

[Gamma] I think so. I think that he feels toward queer people that he's dealing with hypotheticals.

[Gwen] I see

[Gamma] And I think that if he saw, if he looked into my stupid little idiot face, then he would see that I'm not a hypothetical, I'm not-

[Gwen] Yeah, that you exist. 
[Gamma] I am not the only person who wants- the idea of someone wanting you to say "sopranos and altos" instead of "women" is a real person, that's not PC culture, that's not cancel culture, that is a real person who is sick of being referred to in a way that makes no sense to them.

[break]

[Gwen] Would you feel that that connects to the rurality of where your college is, like the location?

[Gamma] I think that could have something to do with it, I think that there are probably people akin to this director at bigger schools who feel the same way he does.

[Gwen] Oh for sure.

[Gamma] I think that my university also is a very queer school. There are a lot of LGBTQ people here, it's the small town, it's like a small artsy town, small artsy school. The queer/straight alliance, whatever you call it, ours is called PRISM, not prison

[laughter]

...is one of, is the biggest non-greek organization on campus. So we have a lot of LGBT people and passionate allies and queer professors and I think maybe the only gender studies in a private school in West Virginia. I think everywhere else they might have women's studies or women's and gender studies but I think we're the only true gender studies program at a private school in West Virginia. So it's a shockingly queer place to be for, again, a rural Methodist school.

[Gwen] For sure.

[Gamma] So I don't- I think that if the location is the reasoning for it, it would more be the location at large and not the school itself, because the school itself, you know, really loves to pat its own back about being an inclusive community. We also have the highest percentage of black students of any college in West Virginia, so I think [REDACTED] is super proud of itself for being so diverse, even though there are almost no black lecturers 
[Gwen] Yeah... is that reflected in your staff? [laughter]

[Gamma] No! [laughter] So it's really- if you're going to use that excuse, you're going to use that excuse about Upshire county, West Virginia, you're not going to use that excuse about [REDACTED].

[Gwen] Yeah, I mean that more in the sense of the whole concept of "oh well we don't have people like that here", that seems to me that that's very much not the case, and that's very much blatantly not the case.

[Gamma] I think there are definitely a lot of visible queer people at [University], especially in the performing arts which I think just makes a further case that the director, if he wanted to, wouldn't have that much of a leg to stand on.

[Gwen] Yeah, for sure. Oh, I should ask- what kind of music do you create, or do you perform and then also do you create music, like composing or original creations?

[Gamma] When I perform not for money, so I sing church music right, I go to a church every Sunday and I sing hymns. That's not what I consider my music. I myself write singer/songwritery pop jazz-adjacent music, kind of genre-less, I'm interested in a lot of different sounds, I'm interested in this weird growly-electronic sound that's taking over a lot of queer music, I'm also interested in rock and in punk and I'm interested in hip-hop and soul, it's all a lot of really good influences, but ultimately the music that I make is just me with one instrument, so there's not a lot of room for style with that that one.

[laughter]

[Gamma] So I think that the subject matter is more important than the genre, I write a lot about mental illness, I write love songs that are written to feel queer. They're not necessarily like the she by Jodie brand of sounding queer, where it's just like same-sex feeling, but something that kind of describes the messiness and the personal conflicts in falling in love. I like music that's anticapitalist, is stuff that I write, music about the great journey of life. You know, cheesy shit like that. And I play music most visibly, with my friend [REDACTED], who's also a queer person. And it's just us with an electric guitar and our two voices singing mostly pop songs. [Pause] So just pop, just write pop, as far as classical musicians are concerned, that's what it is. I 
used to think I was going to be a classical singer. And now I'm not even going to be doing a classical recital ever in my life, so

[Gwen] Cause it was taken from you.

[Gamma] Yeah. I also hate the feminine visibility of being a soprano. I don't vibe with the writing, the text of classical music a lot of times, it's really binary. And even if I were a binary trans person, I don't think I would love it. It's not for me, I would love to maybe one day compose some rep for gender nonconforming people or just people who don't love gendered language, but ultimately I think that I love classical music and it's what I've trained the most in, and I don't think I'm going to use it again in my life.

[Gwen] At least not in a specific performance capacity.

[Gamma] Mhmm.

[Gwen] Yeah, because- - is it fair to say that it's felt like it's been taken from you?

[Gamma] Definitely.

[Pause]

[Gwen] Does music provide you any stress release, or is it just a stressor?

[Gamma] Oh god that's a good one, that's a good one. It's both! It's both for everyone who does music as part of their job, it's both. For me it can be so cathartic to just sit down and learn a song that you like or one you've been relating to. To sing it, I think that I'm fortunate to be a singer because there's this physical reaction you get- you feel the actual vibration of your own body.

[Gwen] Grounding? 
[Gamma] Yeah, I think it can add to the emotional aspect a lot. I know that before, singing classical music I have resonated in a space where it made me cry- not because it was so beautiful, but just because it physically hit right here and here [gestures to eyes and nose] and it made me cry. And that's not uncommon for singers, I don't think, so I- there's a lot of catharsis in it, and also a ton of stress. It's weird to be a creative as a job, sort of, as a responsibility. It's weird to sit down and say "ok today I am going to create meaning" like that's super strange I think. And that's not always what you're being asked to do but sometimes things that have less meaning are more stressful, like "today I am going to remember what modes are so I can help this freshman with their homework". "today I am going to play skills for two hours because I have to pass a piano jury. It's such a weird mish-mash, but I think- when I was a music major I would've said it's more of a stressor, now that I'm a music minor I'd say it's more of a reliever. I also think that being in this pandemic has a lot to do with that (stress relief). I've gotten to the point where I'm listening to music constantly, like I have it on in the background with my zoom lectures and I pause it to comment, I listen to it while I'm working and while I'm sleeping- I constantly have music on. So it's become a much bigger relief when there's nothing else to hear

[Gwen] Yeah, when that's the only thing that you have to pay attention to. I feel we've spoken a little to this, but I want to get to it directly: how do you feel that your gender impacts your music?

[Gamma] This is the first year I've gotten to experiment with that. I came out in the middle of working on my recital rep for my junior recital that was cancelled because of COVID. So I had already made my bed with a bunch of very feminine music. And I was okay with that, I pickedwith [REDACTED] requirements, instrumentalists sort of play whatever they want to play as long as it's half an hour or an hour, vocalists, you have to do one German, one Italian, one French, and you just have to have things by specific composers or from specific eras. And so I really wanted to take that format and make it my own, so I was able to, with the help of my super-cool teacher, figure out a bunch of rep that felt more like me than just going into every one of those books that you have to choose from and choosing one, we really trialed and errored some shit and we spent about four semesters- it would've been a full four semesters working on that music. And I spent half of college working on that music and then didn't perform it.

[Gwen] Of course.

[Gamma] Of course. I- so this has been- I'm not taking voice this semester, I'm taking piano instead, and my piano teacher is working with me on building a songbook of stuff I can sing and 
accompany myself on piano. And I said that I wanted to gear it towards pop music, because I think that's probably more where I'm headed if not jazz. I don't think I got enough time with jazz to get good at it, so I think I'm headed towards pop music. Which is, you know the classical understanding of pop music.

[Gwen] Yeah, the incredibly condescending position.

[Gamma] Yeah. So we've been looking at stuff that sits in the middle to low parts of my voice range, which has become a lot more comfortable for me to sing and it's a lot more rewarding to hear my voice sound like that than it is to just hear myself hit another Ab. And we've been choosing songs by male artists. The first one we worked on was "good old fashioned lover boy" by Queen, which a while ago I would've said was too low for me, a while ago I would have rejected because I used to be a big advocate of changing pronouns in songs. Now it feels euphoric to sing it, you know? It feels like "yeah, fuck yeah that's me I am a good old-fashioned lover boy, I will be taking my prize now, Freddie Mercury Queen”

[laughter]

[Gamma] I also sang Rainbow Connection, something that has absolutely no gender affiliation but is still sung by a male voice

[Gwen] A frog's voice thank you.

[Gamma] A boy frog, it's very clear! It's very clear in the muppets movie that he's a boy frog!

[Laughter]

[Gamma] It's a masculine song and you can't change my mind! I have strong opinions about The Muppets Movie soundtrack! We started the semester leaning toward more masculine music and have now transitioned into singing some Billie Eilish, to the point where I got to get comfortable in this new space of switching where my voice is going to be for a long time, since classical is sort of over for me, this place where I'm training my voice to be is where it's going to sit for a long time. And this music style that I'm working towards is where I'm going to be for a long time, to this year's been very transitional (pun intended), and in figuring out where music is going to take me from here, and I think that obviously my gender impacted the whole experience 
of getting kicked out of the music department, but it has especially informed this whole experience of figuring out where- what music is for me now. Because before, I said I used it to draw positive attention to myself in the same way I did dresses and makeup and I was obsessed with singing the highest notes because I wanted so badly to sell femininity to everybody I met. Now I've put a lot of eggs into this whole 'music' basket, but it's not what I want anymore, I don't want anymore to have... my goal isn't queen of the night now, my goal is like- I'm not interested in being Renee Fleming, I am much more interested in being the lead singer from Mother, Mother

[Laughter]

[Gwen] Being someone more in line with yourself, being yourself really.

[Gamma] Mhmm. Being myself, being that good good individual I worked so hard to be and then destroyed.

[Laughter]

[Gamma] It's weird, because I don't know where my gender is, I don't know where my music is. But, truly I'm recording some stuff, I'm going to put out something that is in place of a recital that plays music that is much more representative of where I am now, and it's going to involve a lot of weird electronic sounds and weird acoustic sounds and a lot of my voice layered on top of itself over and over again. Because I... I think that I can.. I'm learning I can do whatever I want, like gender can be whatever I want it to be, my music can be whatever I want it to be in relation to my gender and I could keep singing queen of the night, I could revive Gretchen Am Spinnrade which I was going to sing for my recital, I could bring her back but I don't want to. I'm not interested in that anymore. And it's exciting and new and also altogether scary, because I am sure lots of other trans musicians have experienced this where it's like: if I- am I just going to be the world's greatest boy soprano? Like am I going to start singing all those Bernsteins where they ask for a boy soprano when they mean castrato? Like is that going to be- and I'm sure, yeah I follow this woman tenor on tiktok, and she has talked a lot about what it means to have spent her whole life working towards being a classical tenor and then realizing that classical tenors are boys and she isn't one. And that's kind of where I'm landing right now, classical sopranos are girls and I'm not one. So it's like finding a new path because I don't think my path is necessarily 
paving the way for non-binary classical sopranos, I think my path is making a new thing that maybe will resonate with other people. Y'know?

[Gwen] Yeah! Absolutely I do.... That's

[Gamma] Sorry, I'm really bad at talking-

[Gwen] No, no you're wonderful! Literally you have gotten to all of my points

[Gamma] I just shit on Dr. [REDACTED]-

[laughter]

[Gwen] I just wanted to check to make sure I didn't miss anything but, no, without even knowing you just like scanned over everything that I wanted to talk about

[Gamma] Sorry!

[Gwen] No! Don't be, you've made my job super easy

[Gamma] I'm a gender studies major, I love getting from point A to point B, I love tying that in, and I love 'backpacking off of that', 'piggybacking off of that'

[Laughter]

[Gwen] Seriously though, thank you a lot. Is there anything else that came up that you thought of that you really want to speak to? 
[Gamma] Umm. [pause] Queer musicians deserve more space in classical music, but I don't want every queer musician to feel like it's their responsibility to make that space for themselves. I tried it, and it sucked. And I've discovered that what's better for me, at least, is doing something different. And I think it can be really scary because classical music is such a harsh reality, such a harsh venue, that it can be really really scary to imagine yourself venturing off from that. But it's so much better than staying within a, a system of art that was built to systematically oppress people.

[Gwen] Yeah.

[Gamma] Cause classical music is beautiful and has so much value, but also is so deeply flawed in so many ways, that I don't think that you should be afraid to do something that isn't it. And it might be a lot better for you not to. And I don't want to just say "fuck classical music, give up on it!" because that's not everybody's truth, that's my truth. And I still love it, and I'm still going to analyze symphonies for fun, but when it comes to performing, if it- if the space isn't there for you, it's not your job always to make it. It just isn't there sometimes, and you aren't letting down the future of queer classical music. You are preserving yourself, and preserving your love of music, which I think is hugely important, because it's really easy to hate music sometimes, it's easy to hate music when you're a cis heterosexual person who's studying music, and it's especially difficult when you're being forced to sing texts that don't make sense to you and when you're being called things you don't want to be called and when you're being asked to dress a way that doesn't feel right to you. So it's- yeah, it- it could be worth it, but also don't be afraid of it not being worth it. I was really afraid of it not being worth it, and it wasn't worth it and I was right.

[laughter]

[Gamma] There you go! That's my inspirational speech.

[Pause]

[Gwen] Well, thank you so much! 
[Gamma] Of course! Thank you, this was a lot of fun. Thanks for just like chit-chatting with me.

[Gwen] Yeah! Thank you for participating, I will likely send a copy of the completed project your way, that would be with information redacted of course.

[Gamma] Yeah!

[Gwen] Yeah, that's- and of course I'm going to be talking about this for the next 9 months

\section{[REDACTED]}

[Gwen] So, the conclusion of this recording is at 4:05, this is Gwendolyn Emler, and the date is still October 22 $2^{\text {nd }}, 2020$.

[Gamma] Still is!

[Gwen] It still is!

[Laughter] 


\section{Chapter Five: Respondent Delta}

[Gwen] Hi, this is Gwendolyn Emler, the date is March 18th, the time is 4:33PM. This is number 00100431821.

[Laughter]

[Gwen] Hi! Do I have your permission to record?

[Delta] Yep!

[Gwen] Neat! So, do you want to introduce yourself?

[Delta] Yeah! My name is [REDACTED; Delta], I use they/them and he/him pronouns. I'm a senior, this is my last semester at my university, I'm getting my bachelor of music in voice performance as well as my bachelor of arts in integrated and contemporary performance, or I think it's contemporary and integrative performance, I don't know the exact order.

[Gwen] Something like that.

[laughter]

[Gwen] Well neat! Let me see... How did you end up at your university?

[Delta] A combination of three to four different things. One, they were one of the music schools that accepted me into the voice performance program, because I started as initially just a voice performance major. I live in Pittsburgh, about an hour away or so, so it was just far enough away that my parents wouldn't be there all the time, but close enough that they could still come support me. And my university offered me a really good academic scholarship so you know, just made the most sense for all of those reasons. Since coming here I've been very grateful that I didn't end up at a conservatory, where I might have been pigeonholed into one thing-- I've really found my niche a lot here.

[Gwen] Yeah

[Delta] Beforehand, I didn't really know too much, like I didn't start singing jazz until after I got here, but it's been kind of... it's like the right door opened. 
[Gwen] That's good to know! I had a similar experience with that. I went to an undergrad school that was just far enough away, and it lets you breathe, you know?

[Delta] Yeah, certainly.

[Gwen] Oh, you talked about the jazz program, how'd you get into that?

[Delta] That is actually probably my number one like "the right doors open the wrong ones closed" story. So I actually auditioned for the musical theater program here multiple times and like got denied both times, and I was kind of upset about it but then I was in my English 101 class with the professor who's actually the wife of the jazz professor--

[Gwen] I thought I recognized the name!

[Delta] Yeah, and I wanted to do a little interview paper on jazz. My concept of jazz at the time was "oh Stevie wonder!" like "oooh jazz" like I literally knew $0 \%$ about jazz. So she goes "oh so funny story, my husband's the jazz professor, you should interview him for your project here" and I said "ok" So I went and interviewed him and it was really cool and he says "well you have to come sing at jazz night" and I was like *stutters*

[Gwen] "I have to what?"

[Delta] Lying like "sure why not? This is the scariest thing I've ever done" and so I did and I sounded like little musical theatre me singing a jazz standard, but I did it. Then he said "yeah ok, that went really cool, you should come sing with the jazz combo next semester" and I was like "ok," also mildly terrifying, but really exciting and cool. It was at that point that I was like "oh shoot, I kind of really like this, like I kind of want to take lessons. Because there have been a couple of vocalists that took lessons with [jazz professor] last semester, and I was like "maybe I can do that." So it originally started with minoring in jazz, but then when I picked up my second degree, we switched it and moved all of my jazz lessons and stuff into integrated and contemporary performance. So it's very much like the wrong doors really closed and the right ones opened. I think it ended up working itself out in a way that I didn't put myself in an unsafe situation later when I came out. To my knowledge the musical theater department is not the most... it's pretty binary.

[Gwen] Mm-hmm.

[Delta] I mean there are many other issues that I could talk about for a while, but in general musical theater programs are binary. 
[Gwen] Yeah. By all means, if you want to talk about that, sure!

[Delta] Oh I mean it's also like-- the musical theater professor that started here my junior year and has since resigned because of other things, they were about to put on Head Over Heels like right when quarantine started, which is a very gay musical like there's lesbian lovers and there's a nonbinary character. I was the only nonbinary person that auditioned for the show, so one might imagine that I would get the nonbinary role, and, you know who didn't get the nonbinary role? It was me.

[laughter]

[Delta] And out loud, the director said to his whole class that he was not trying to make a statement with any of the castings, even though the entire reason that they- that we had the rights was because the guy who owns the rights to the show was an alum and wanted to make a statement by letting [university] do the production first. And he also said to multiple students after callbacks that the cisgender girl that ended up getting the role-- that was originally played by Peppermint, a nonbinary drag queen-- that her rendition of the monologue was just "so moving" because she "really expressed all of the nonbinary emotions." and I was like...

[anguish]

[Delta] That's so lovely, like I love that and then this year they're doing Rent and there's like one black person in the whole class.

[Gwen] Yep! Yep.

[Delta] I think I honestly dodged a bullet because maybe I could have helped make that better, but... I dodged a bullet.

[Gwen] You definitely did, like I've had run-ins with musical theater like that like, all the time, and it's just like--

[Delta] And then it's just like- you know I'm friends with most of the theater department and they were like-- you know there were a couple of them that understood where I was coming from, but most of them were like "oh it's ok, it's just a role" like that might have been the only time in my entire life that I would get to play a role on stage that matched my gender identity.

[Gwen] Exactly

[Delta] Don't “it's okay" it to me, it's not okay, like, what? 
[Gwen] Yeah, it's like this shooing away like "oh no no no."

[Delta] And those are just a couple examples of what I'm sure many racially and homophobically motivated things that that department has done. And [jazz professor] is generally a lot more progressive- granted there's not character things to keep in mind with the jazz department, but you know he's very socially active- like we had our Black Lives Matter concert last year, he talks often about how jazz is a black art form and it started that way and how if you don't know the roots, you can't really perform it genuinely. With the Black Lives Matter concert, it was more than just like performing songs by black composers, we also donated to the NAACP and were very vocal about it. He still is. It's- you know, no one's perfect, but it's definitely a safer space to be in.

[Gwen] Yeah definitely, that's exactly it, the actual action that's being put with it, instead of just- that's in the forefront of my head because that's what we're discussing in a lot of my classes, just talking about those concepts.

[Delta] Yeah, there's a lot of talk and no real actions. Unfortunately that happens a lot. There's a group of like 6 theater and dance alumni called [alumni organization] and they've been trying to work with some of the theater and dance faculty to do more diversity, equity, and inclusion work and it's... it's basically leading to a bunch of performative nothings.

[Gwen] Yeah.

[Delta] Because, you know, then the teachers feel like they're being attacked, even though they're just being asked, especially the tenured professors, are just being asked to use their tenure to make positive change in the environment, which I'm really glad that we have [academic professor]- man, they're just my favorite ever.

\section{[Redacted]}

[Gwen] "it's a lot of performative nothing" is it in a nutshell. I mean that's not just us, that's nationwide, honestly. Thankfully at least a little bit, especially with people your age, it's this changing tide. I know I say your age even though we're not even three years apart, but it's just, we're in a different position.

[Delta] Yeah. 
[Gwen] Let me see... Now, I know we just spent a lot of time talking about you performing with the jazz ensemble but, as a whole, what music do you create and or perform? Like what music do you perform, and also what music do you compose or create, because I know for you that's--

[Delta] Yeah, so for my classical degree I perform all art song and operatic works in the classical style. I've never composed anything in the classical style, although my plan is to take previously composed classical works that are in the public domain and turn them into other things. We're getting some of that. Anyways, I've performed in two operas, so I'd say right now my split is 50/50 jazz and classical. I also love performing musical theater. I've been in several musicals, but none through the university because, like I said, the theater department doesn't really like me, which is ok. And yeah, so... sorry I lost my train of thought there- I also want to get more into performing funk, I'd love to perform in a rock band or something one day, I think that'd be the coolest thing. I have a lot of genres I want to explore once I'm done with my degrees, and although I don't want to pursue a professional opera career, I definitely want to keep classical music in there just because I think the fundamentals of the vocal technique are really good, as well as just having that rep in there. It'll make me money I think. If I can benefit from the patriarchy, I will.

[laughter]

[Delta] That's my opinion on that! But yeah like right now it's about 50/50 performance wise. I really only compose jazz, folk, indie, poetry. I mean like my genre is queer, jazz, funk, poetry, like it combines all those elements, but I've also done some more indie acoustic stuff. That's definitely a side of my life I want to focus on more once I graduate and don't have to be in 13 classes in a semester.

[Gwen] Yup! [laughter] What, like you said at the top, like "what, actual free time? What is that?"

[Delta] Could not be me.

[Gwen] Simply could not.

[Delta] Free time? Never heard of her!

[Gwen] Who is she?

[laughter] 
[Gwen] I also- with the music that you write, I am also aware that you just released an album, actually! Could you talk about that?

[Delta] Yeah so this album, it came out of my honors excel project which I proposed and applied for and everything through the encouragement of [academic professor]. Initially I proposed it as a seven-song album made half up of covers and half of originals talking about feminism and sexism and stuff, and touching on other things. Then like three months later I came out, and I was like "mmm you know what, I have a lot to say actually about this thing instead." I think that there's a big gap in the jazz world talking about feminism. There's a lot of pretty sexist lyrics and stuff like that. Which is a problem, but I found myself just needing to transition the project as I transitioned, simply because I needed to have a starting point, much like you have to feel solidified in yourself. It's called Queer Vespers and its part of my-- I don't want to say my coming of age, but it's like my opening statement, like the opening prayer of a church service. Like "here's the struggles and joys that I've found of being queer, here are the prayers that I have for the future," stuff like that. So it ended up all being original music with elements of electronics, tap, and poetry. I guess there are four main components to my honors project as a whole, one being the research behind it. Lots about jazz poetry, queer jazz artists, lots of listening and lots of practicing. The actual writing I did partially in electronic music composition lessons and partially on my own. Then recording, which was really cool- we actually did the whole recording in three sessions, which is crazy for a first recording. And partly due to COVID, our pianist could only be with us for one session, so all of the instrumental tracking except for the one track that's just me and the bass happened in the same session, which is just crazy.

\section{[Gwen] Yeah!}

[Delta] It was like a seven hour session and two-and-a-half of the hours were on the song with tap and it was- oh it was really long. And you know, the release goes in with the recording, and the performance part. We're doing this live recorded concert version. It's not going to be livestreamed, but it's going to be recorded as if it were a concert version of the album, with full lights and stuff. It's actually in collaboration with the school of music and the school of theater and dance, I think... partially because my boss is amazing and partially him seeing a need for... a student needed an independent study, I needed a performance of this album, so it all worked out like that. But also, I think in hopes of bridging the gap a little bit between the school of music and the school of theater and dance, because right now I think people just get into rifts and don't want to work together with each other. Hopefully that'll be more clear moving forward. And then the other part is outreach, because my school has its land grant mission and part of our project is saying how we're going to give back, so I created this educational video series on queer jazz artists. Which was not only informing for me but for informing for everyone, even [jazz director] was like "I didn't even know that Bessie Smith was bisexual" and I was like "the more you know" and people were like "I thought Duke Ellington wrote A-Train" and "no that 
was Billy Strayhorn", you know? And so it was informative for everyone, and I presented some of the material from it at convocation this past week, and then we're putting together the videos and stuff in the coming weeks. I'm hoping to release it sometime for pride month maybe but we're still working to see if we can get any larger organizations to sponsor or share it and stuff like that. So that's also in the works, but that's like all of the components of my project.

[Gwen] Yeah! See, like, all of that just makes me want to scream "[university] should have its own label, or a publishing-- like a student run publishing"

[Delta] I mean we have our record label. [Label] is affiliated with [university], I don't know if they do publishing though specifically. So yeah right now there's-- [label] is like sort of a part of the industry program, and a lot of students work for the label and stuff like that. And then there's [other company], which is the older part of the label, and they sign artists, they sign people who win [local competition]. I think there was a West Virginia talent show and they signed the person who won that. And in my case, we had our projects and then we proposed them to [jazz director], who said "yeah I've heard you sing before, let's do this." If you come with a proposed project, they're willing to work with you and because it's for the most part student run, I didn't incur any recording costs or anything. Which really helped in terms of the grant money for my project, I was able to pay my musicians really well and still have money for advertising. Then there's [other local label] records which just formed this past year, and it's entirely student-run and they're working on a compilation album right now of a bunch of different singles from local artists. They're a little bit smaller, a little newer. I think there's a lot more newer music industry students working on that, like for me I had a student producing my entire thing, people who've been working with [label] for the whole time and I can go and work with the newer industry students the whole time. I don't know if they publish specifically, but, we do have a pretty robust music industry program which is surprising in the middle of nowhere, west virginia but, I, thank goodness you know?

[Gwen] Yeah really.

[Delta] If you told me four years ago that I was going to go to [university] and start singing jazz- not only that, but by the time I graduate I was going to be graduating with two degrees and a queer jazz funk poetry album out in the whole world, I would have literally laughed in your face.

[laughter]

[Gwen] Also, you're not cis! 
[Delta] Surprise! I was just- I was having my baby gay awakening, my first gay awakening right as I was coming to college- well my senior year of high school. I could talk forever about those "hmm I should've known” moments.

[Gwen] Please hit me with them, if you're comfortable with that!

[Delta] Oh my gosh, well, it was- I think one of the biggest ones was- so I came out right at the end of my sophomore year of college as nonbinary, and it was much more seamless than my first one because I knew my parents would be accepting. My mom was the first person I told. It was just much calmer overall than last time. But, at the beginning of that semester, like that January, I thought "hmm, maybe I'm nonbinary" and then I thought "no that's silly, why would I be that?" and then I ignored it for the entire semester. It was things like crying every time I put my choir dress on and it making me feel ugly and making me feel bad. And I would get so so upset at it that, even before I came out I emailed [choir director] and was like "hey can I wear a suit next semester" and she said "yeah sure whatever." I would say things to my roommates like "well I'm definitely a girl, but this dress just makes me feel so bad" and I could see the looks on their faces like "yeah, sure, okay" "sure, whatever you want"

[laughter]

[Delta] And you know, it's fine, girls can be masc presenting and that's perfectly acceptable and normal, but it was just the way that I would say it. I would get so defensive about being a girl. Then there was this whole thing because I started wearing pants to all my classical performances, then one week for voice recital hour I wore Doc Martens and the voice faculty was in a tizzy because they couldn't focus on anything besides my shoes, because even though I was wearing a nice shirt and nice pants, the fact that I, identifying at the time as a girl, was wearing boots was offensive. Even though guys walk in there all the time with their Doc Martens and no words are spoken about that. It was this whole big thing, and, you know, I was more upset about it I think because I didn't know I was struggling with gender and stuff, so I was taking it as a personal attack on me. I mean you can say things about being classist, and that'll be a whole other conversation, but it was this whole big struggle and I was just trying to do something that felt genuine to me, and they were like "oh but that doesn't look professional" and it was a whole big thing. I had also been seeing someone nonbinary at the time, and we had had several conversations about how they had typically dated more masculine people, and so them dating me was different, and I was like "maybe it isn't that different." Then we had several conversations about how I felt that anytime I had ever dated a straight guy they were really intimidated by me and it was this really weird dynamic, because I have a lot of masculine energy, that's just how it is. They were always... offended is the wrong word, but they got really defensive about it. Like if I tried to be macho or whatever., I definitely suffered from aspects of toxic masculinity at times, and I think that's me trying to overcompensate a lot of the time. In any case, it didn't 
make sense until I was walking on the rail trail with one of my graduate student friends one day and she was talking about her partner's experience in the voice program and being gender-fluid, and because he had come out in the same semester that I started dressing really masculine and she was talking about that, and I said something like "I'm definitely a girl, but" and I don't even remember the rest of the sentence because it was like a slap in the face, and it was in that moment that I was like "oh that is so not true, and I gotta figure out why." So I spent the next three days just constantly doing research on the computer searching things like "can I even be nonbinary because I don't feel like a guy, like I'm definitely not binary trans, but what is nonbinary, and is there sublabels" and just what is going on. And at the same time I was auditioning for a summer show and I was really depressed that I didn't get cast in the only one I auditioned for, and so it was like a "what am I going to do this summer? I'm having a gender crisis and I need to figure this out before I tell anyone about it, because I just need to know for certain". So I finally figured it out and I was like "I don't really know what my pronouns are, I don't really know how I identify besides this, but I know I'm not a girl" and I went and the first thing I did was tell my mom because the first time I came out, it was a whole mess and I.. it.. Mess is the wrong word-- I was really worked up about it because I didn't know how my parents would respond. I sat down with my mom and I told her the same thing about how I was walking in the woods and how "I don't know, I think it's subject to change" and she was super cool about it, and then it was really funny because the next morning I ended up getting cast in American Idiot as Extraordinary Girl and I thought "this is really funny"

[laughter]

[Delta] It was an awesome role, I would do that role again and again for the rest of my life. I don't necessarily have a problem playing binary roles, I do have a problem if there is a nonbinary role and I audition for it and I dont get it. But this is a show of binary roles and I auditioned for it knowing that, so I think that's fine.

[Pause]

[Delta] Oh, that was just to say, I think.. What was the question you asked me?

[Gwen] If I didn't ask it specifically, I think I was thinking about how coming out plays into what you were doing with your composition.

[Delta] Right, ok!

[Gwen] And your experiences with that whole hatching process. 
[Delta] Yeah, ok ok ok. I feel like I'm loading, like a little circle on my head. Ok, so I think I'm going to go to my composition and then tie it in as I go through. My composition, I wrote as a narrative work. It's not necessarily "the boy went to the store and then got bread and milk and then came home and that's the end" it's not a story in that sense, but it's narrative in the sense that it's cohesive from beginning to end. Not only lyrically and thematically, but musically too. So I start in $\mathrm{C}$ minor, then I continue in $\mathrm{C}$ minor. Then I go to $\mathrm{Ab}$, so the flat six, then in the fourth piece I transition- haha- from $\mathrm{Ab}$ to $\mathrm{G}$, so I move down a half step, and then $\mathrm{G}$ is the 5 in $\mathrm{C}$, and then from G I go to F, which is the IV, and then one. So I have an amen at the end, which gives the whole album a really final feel. Also in the last song, it's a really gospel-y I-IV-I cadence through the whole vamp. So in the sense of that, it starts off in minor because it's this song that I wrote from the perspective of this moment when I should've known I was gay, but I didn't. There was a vigil that we had in my hometown for the Pulse nightclub victims, and I went with who would later be my girlfriend, and she was leaving for Germany soon after that. So we were driving home from the vigil, and we stopped in front of her house. We both got out of the car and it was pouring rain and we just stood in the rain and hugged, and should have kissed but just hugged for like 30 minutes and I was thinking the whole time "I should kiss her", "wait I'm straight", "what's going on". It was this whole thing, and then for two months I ignored that because she was in Germany the whole summer, and it was this whole thing. It was just the dichotomy of having those feelings at the same time as we had just experienced this really tragic event where so many people had just been killed. I was feeling such deep feelings and thought "well this is scary, maybe I'm just straight, maybe I'll just go with that" and it's just that combined with my very Christian upbringing, it was a lot. So that's where the first song comes in. I was going to go a completely different direction with the song, but I was having some trouble with one electronic thing that caused me to have a full meltdown, and then I was thinking "the only thing I have right now is this freaking heartbeat, this pulse." Then I connected pulse, Pulse nightclub, gay, gay night clubs, and then it all came together in about an hour and a half and I thought "oh my god, this is what the song has to be." I wove, I recorded myself saying the names of all the Pulse nightclub victims and that's part of the backing for the whole song. So it's not just an homage to them, because I think that that's really important, but I didn't want to commodify that so I had to put poetry over it that says "hey this is something, we can't forget them because if we forget them then there's no one to remember them, and if there's no one to remember them, then what have we fought all these years for?" I don't know, it came together all of a sudden and it was just there. It was funny because I wrote it when Trump was still president, so I say like "and our president still wants to deny us healthcare" and I was recording it with the band at some point in January for the video series, and one of the band members goes "oh well not anymore" and I said "well, ehh, I don't know about that, I don't know if we've got a much better one in office right now, so."

[laughter] 
[Delta] It's like those memes you see on Twitter that's like "Us: can we please have equal rights? Republicans: No. Democrats: No (she/her rainbow heart)"

[Laughter]

[Delta] Anyways, moving on to my second piece, it flows right through the first one, and it starts with a Byzantine chant, like an actual one from the church, and it bookends the second piece because I talk about how the church repressed my gender and sexuality for the first 20 years of my life. I mean I went to church camp for 11 years-- I spent actually a couple of hours on the phone with a friend of mine talking and discovering some religious trauma that I still hold, so it's not... I realized last night that not only do I have trauma related to gender and sexuality as related to the church, but I just have religious trauma in general related to things that happened in my 11 years in church camp and youth group. And so it's just-- something I said in an interview with my friend, I said something like "if I had heard more explicit queer representation in the media that I was consuming as a kid, I think maybe I would've realized sooner", or rather more explicit positive queer representation.

[Gwen] Yeah.

[Delta] Because I specifically remember reading a book in seventh or eighth grade called The Miseducation of Cameron Post and it just got turned into a movie or a Netflix thing, and I was like "oh my god." It was one of those scenes where the girls kiss and I felt butterflies but at the time I thought "I shouldn't feel that, like whatever," something like that. But I was in 7th grade, what'd I know about anything? And so I was feeling that for no reason, but of course all the books I read in middle school were depressing as fuck-- sorry, excuse my language.

[laughter]

[Delta] So like all I knew about gay people was that they suffered really badly, and I wrote a paper not on that but actually on romanticization of self-harm and suicide in young adult novels, and how that contributes to the mental health crisis that's going on today. Because you read the books and you're not given proper resources to understand and not pick up on the behaviors of the main characters. That's actually one of the coolest papers I've ever written because I thought of it and thought that someone else had to have done it already, and I had to dig for research on that one.

[pause]

[Delta] Back to gender and sexuality, growing up in the church, my grandparents were the first directors of the Greek Orthodox youth camp that was in our metropolis, so we always went to the 
same church and did the same thing. So, from the time I was in 2nd grade, I was going to stayaway camp for a week every summer, and getting post-camp depression, stuff like that. It was always "oh you can love gay people but you can never be one, and you can't condone their actions." So when a couple of my friends started coming out to me, I actually went to my uncle who's a priest, and I said “they're the nicest people ever, how do I deal with that?" and he pretty much said "yeah, you still show them God's love, but I pray my daughters never try to bring a girlfriend home. Because I'd let her in to show I truly love her, but I pray that would never happen." So that was something else that further delayed my process of discovering that I was gay. And I've since had conversations with him about other things that are less fucked up, but more fucked up in a way. Like he's rescinded that opinion and become accepting and has acknowledged that "to have a relationship with God you have to have a point A in your body." But there's a lot of stuff to unpack with that, which I won't go into because it's not really relevant. So I wrote that song really about that, that's the second song. It's juxtaposed because that was such an integral part of my life and now it's like "ok if you're saying God is loving and you're saying I'm made in the image of God, then all of these other things should be true and God will love me because I'm trans." I'm not really sure where I am on religion at the momentwell I'm pretty sure and it's pretty not religious, but if you're saying these things are true, then these things should also be true. I will use "Lord I have cried unto you, hear me" and you're going to hear me, and you all who have also cried unto the lord are going to sit there and listen to me talk about this, and you're going to sit in it and take it in.

[Delta] Then that moves into Gone, which is sort of a transitional piece in and of itself, because the first two verses are "I know who I am, but no one else thinks of me that way" and then the third verse is "hey, I'm going to be me, and it doesn't matter, I won't ever be gone" and it's like setting an intention in a way. Then the fourth piece is just spoken word and bass, and it's this poem about this interaction that my parents and I would have as a kid where one would go "I'm turning in" and the other would say "into what" and before you'd go to bed you'd say you're turning into a dragon and stuff like that, so I turned it into this analogy about me transitioning and wanting to turn into something else. Like transform-- a butterfly has always been a butterfly, but first they were a caterpillar, and the caterpillar served them well at the time, just like my name and my body served me well at the time. But, that's not how they were meant to be eventually, and I think if God, for example, could make a butterfly that way, he probably makes humans that way too. And if you try to argue with me on that, "ok Karen why do you dye your hair and cut it, why don't you let it grow long, why do you have glasses" God made you without perfect vision, don't fix it. God made you with the brain you had as a child, why did you go to school and learn things?

[Laughter] 
[Delta] I could go on with that! Anyways, the next song Gay Club Pt. 2, it shows the duality of what a gay club can be. A gay club can be a very scary place, but it can also be your safe place. So I just tried to make the song happy and a celebration, like it needed to be a swing revival with tap, which was something I thought about from the beginning. It's also, I think for me it was something I was really insecure about because I've never taken a tap class, I've just picked up what I know from musicals and teaching myself. So it was really an "I don't have to be perfect at this to enjoy doing it and celebrating it" and that was unintentional on my end,but that's how it ended up being. I think it inspired me to incorporate more dance into my things in the future because I think that, visually, that resonates with a lot of people. That song was probably the most fun to record, because it was just really fun getting to play around with different sounds and actually-- I feel like I developed a really good relationship with the drummer after that, because you know, we were tapping and he was mimicking the sounds I was doing with his drums, and it freed me up a lot in terms of my vocal expression, too. So that song's all about being free. And then we have I Hope I'm Yours, which is just literally this cheesy love song because I think we need more love songs that are explicitly queer. I was going to write something in the eleventh hour, like very cheesy. Besides "you are my queer love", the lyrics aren't explicitly queer, but I'm just showing that queer love is normal. It's special and sacred, don't get me wrong, but it's also... we can have our love-dove moments like all the straight people can, you know?

[Gwen] And deserve it!

[Delta] Yes, exactly, exactly! And then Space Gay, I just think it's funny because I don't think I ever intended it to be called Space Gay in the end, but it felt right so I left it like that. But, it was actually the first song I wrote, which is really weird for me because I tend to write a lot of sad poetry, when I'm upset about stuff. So the fact that I was writing this really motivational thing... I don't know, I try to not start with the end, but that's just how it happened, and I wanted to just let that happen. It's kind of a call to action, but it's also an affirmation that everything will be ok, to not give up, but to remember all of these things. I touch briefly on things like "here are some really inspiring things, don't forget about them, but also don't forget not to bury voices underground." I think something that I initially thought with this project, in the way that I grew personally, is that when I was debating doing stuff on feminism, I also had all of these other forms of activism like Black Lives Matter and speaking for all these other minorities, and I thought "wait, I can't speak for all these minorities, but what I can do is open up the conversation and speak for who I am and make other people feel safe to speak for who they are" which was a big mental shift from the white saviorism that I grew up with, especially in the church in a rich white public high school. Personally, it was a really big shift, realizing that I actually can't talk-I shouldn't, I could, but I shouldn't talk over people who know more about those things but I should create space and acknowledge, you know? Like I say "my trans sisters of colors" in the first song, and we have to acknowledge that those things are happening in order to fix them. But, 
we can't talk over people who are expressing their personal experiences. Anyway, I just took you through all the songs, let me know if you have questions because I kind of talked at you a lot.

[laughter]

[Gwen] I cannot tell you how much I adore all of that in the best way. I actually had your album played for me and it was just being described to me from the perspective of someone who was listening to is, and this album is this thesis, like so much of- within everything, just interwoven into what you're doing is creating this trans sound. It's-- because that was what I set out to find, was trans music, and here it is so plainly just, "here you go!" Not that it's entirely relevant, but I am curious: you talk about keys for the pieces as they go along being this chord progression, are there any other elements of the church that you incorporate into the pieces?

[Delta] Yeah, so it's actually funny- I mentioned the Byzantine chant, that's the most dominant element of the Greek Orthodox church, which is what I grew up with. We don't actually do a lot with the amen cadence in terms of what our traditional church music is, because all of our music is pre- when that stuff was invented. That kind of sounded like "ooh ours was invented first" but like, technically yes, Greek Orthodoxy stays the truest to what the original Christianity was, which was pretty bad actually, pretty terrible if your church hasn't changed in 2000 years but the entire rest of the world has.

\section{[Laughter]}

[Delta] Yeah, it's just... I think that's really it in terms of this album, however I have faint inklings of things that I'd like to do in the future that... even now, in my head: bible passages, but just as sacreligious as possible. Because I just think that it's great that they get to disrespect my entire being and say that I don't even exist, but if I say one word about the thing that was written by cis men back in the day... God is a metaphysical entity, energy that we've given a name to. I don't know how religious you are, but that's my view on things. I kind of got the vibe we were on the same page. Because I do have trans friends who are still Christians and fairly faithful, although it's been more and more of a struggle given the recent papal edict. I think a lot of the queer people I know who are still religious have a very different perspective and are more understanding of the intentions behind the religion, because I think religion in and of itself isn't a bad thing, I just think that the ways its been interpreted and practiced are the bad thing. If you boil it down, most religions have the same core concepts and really speak of the same energy, at its center. If your religion's not based on love, you've probably distorted the message. You've probably messed something up on the way. The word 'homosexual' was not in the Bible until 1948 , they literally changed it from 'boy-molester' to homosexual.

[Gwen] Yeah 
[Delta] And people don't still understand that!

[Gwen] Literally that addition was politically advantageous for the pre-McCarthyist government of the United States, like that's all that it ends up being and that's so frustrating seeing that.

[Delta] Right, yeah.

[pause]

[Delta] Oh! Other elements of the church. No, not in this album, it's really just the Byzantine chant. Although, in that song, even though the only thing I took directly from the chant is at the beginning and the end, I stayed in the chant feel when I was writing the melody so that it would really be juxtaposed with the funk beat, the jazz organ, stuff like that.

[Gwen] Kind of like queering those elements.

[Delta] Oh yeah, exactly.

[pause]

[Gwen] When did you actually start working with music-- when did you start playing or singing?

[Delta] I think I've been singing since I was little. I had general music in first through third grade, but then I started playing the violin in third grade. I knew I wanted to play the flute, so it was more that I just wanted to be in the orchestra. So then I played flute from fourth to when I graduated high school. I still have my flute, I've been meaning to pick it back up but I've been a little busy. Anyways, so then I did choir in fifth grade, but I couldn't do band and choir in middle school, so I picked band. Then the first time I did a musical was in 7th grade, it was The Music Man, very exciting. I can still remember the little spoken word solo I had in Rock Island at the beginning. It was that first moment when the curtains opened that I knew I wanted to be performing for the rest of my life, but then I denied it for several years because it was-- remind me to come back to the jobs I wanted as a kid in a minute. Now I've done a show almost every year ever since, sometimes two. I didn't really decide I wanted to go into music in college until I was half way through my sophomore or junior year, which is a lot later than people decide normally-- which is crazy. And there's a whole classist element and stuff like that, so. Like how a majority of people that have music scholarships, like school of music scholarships at my school are rich white kids from northern Virginia. And I'm like "ok but they're the ones who paid for hours and hours of lessons." I had half-hour lessons for two years and I thought that I was lucky, but there are people who have been training in musical theater from the time that they were 
babies. My parents lived in a rich white neighborhood, we were solidly middle class, but we couldn't be paying thousands of dollars a year for extra classes like other people could. I remember in seventh grade I took an acting class, and I did the musical, and then in eighth grade, I took a dance class for one semester and a voice class for one semester but I had to pick between voice and dance because my parents said I couldn't do both and the musical. So it blows my mind that I did a lot of things in grade school and there are still so many people who are richer than my family and they have all the resources, especially in musical theater programs. And in instrumental programs too, but you know you have band during the day so it's kind of different.

[Gwen] Yeah, it's like you said, the classicism that just runs through it.

[Delta] Right.

[pause]

[Gwen] Yes, the wealth disparity and the toxic culture that is so obvious and apparent.

[Delta] Right. I think you'll find this funny, the jobs I wanted to do starting from the time I was very little. First I wanted to be a builder, because my dad's an architect. I actually wrote him a helpful little guide in kindergarten called how to build a house-

[laughter]

[Delta] -because he didn't already know that. He still has it, which I think is really funny. Then I wanted to be a nun, because in fifth and sixth grade that's a perfectly normal thing for a young girl to want to be who is totally not indoctrinated into a church-like cult.

[Gwen] It's not a cult, not at all (sarcastic)

[Delta] Right, yeah. A nun and also a missionary, so that's what I wanted to be, that's what I wrote on the sheet in fifth grade. In fifth grade, I was in fifth grade! That is so concerning on so many levels.

[Gwen] So many, yeah!

[Delta] Yeah, and the fact that my role model, that I wrote on the same sheet was Troy Polamalu, a football player, because he did his cross before every game to pray to Jesus that he would win the game. Like, to this day I am realizing things that I recognize as not normal. So then I moved on from that and I wanted to be a special agent with the NCIS or the FBI or something like that. I 
went to police camp for two years and because I was the best cadet the first time, I went to the state police honors camp the second time. ACAB, as we know. But I also didn't understand that at the time. Also it was definitely a camp that was supposed to be for... looking back on it, it was where a lot of parents sent their kids what were behaving poorly, and then a few random white kids that are from affluent white families who sent their kids there just because. And then those kids ended up doing well and going to the honors camp, which was this silly thing. But it was to learn about law enforcement and not to punish your children. It was very weird, I could go a little more into that. Anyways, it felt relevant to me or whatever. And then I decided that I wanted to do music, and I actually auditioned for music ed, voice performance, and musical theater programs which, why I did that I don't know, I like to torture myself I guess. It was actually when, on my initial letter of acceptance at [university] that they just had music education because I had auditioned for both and I was really upset about it, that I realized that I wanted to do performance. And then my mom called to ask them something else, and they were like "yeah your kid got in here for performance, we're not sure why it didn't say that on the letter too" and she said "oh well that would've been nice to know four days ago when my kid started crying about this, so."

[Gwen] I know, I kind of see a little bit behind the admissions curtains sometimes, and it's very likely it was just someone's mistake.

[Delta] Yeah. So that's how that happened. I picked some weird schools to audition for. Oh, I was talking with my jazz teacher before this about how I had a teacher that my parents could afford whose primary was piano and clarinet and she also did voice lessons. But, she picked really bad repertoire for me to audition with and didn't know which programs to audition for, so I auditioned at [five universities], and.. I remember one more, I know I auditioned at six schools... I had six in-person auditions

[Gwen] Ugh!

[Delta] Which is comparatively a low number, actually because like music theater people will do like twenty.

[pause]

[Delta] Anyways, so one of them I shouldn't have even bothered applying to because I wouldn't have been able to afford it, so I wasted my own money on the fees. Even if I had gotten into that program, I wouldn't have gotten enough in scholarships to pay for $\$ 70,000$ a year, which is ridiculous. Another one, it was smart that I applied there, it was a safe choice-- I knew I would get in-- well I didn't know, but I knew some of the teachers there. It's mainly a music education school, so if I was going for ed and performance, it wouldn't have been hard for me to get in. 
They offered me a lot of money, but since their tuition is so expensive it was not even worth it to consider. But, it was the first audition I did, and it was nice to know that I got into the school. It gave me a good little confidence boost, because ahead of all my other auditions, I knew that I was already in there, which was a safety net.

[Gwen] Yeah!

[Delta] And then for the level that I was, having one reach school should've been fine, but I could've applied to others, more programs like the one I'm at now, because that's the level that I was at when I came in. I wasn't, like... when I listen to videos of myself, I'm surprised I got in here. But actually, I've talked to several of the voice faculty-- I did a mock audition here my junior year of high school and so they saw that I got a lot better between my junior and senior year, and they were like "hmm, we want to work with this kid." I wish I'd been able to do that with more of the schools. Actually, it made me feel really validated that I got into another program for music ed, but I think that was partially because of my interpersonal skills during the little interview, because I was... like I'm passionate about helping kids out, I'd totally teach private lessons, but I didn't want an education degree because I could not teach in public school. I know myself-- I just could not do that. And I don't want to be the bad teacher for some kid that makes them hate music, I will not. I think all of that's to say that I think the audition process is super messed up.

[Gwen] Oh yeah, absolutely.

[Delta] Especially in terms of a queer standpoint. Like I've talked to some of the faculty here about maybe putting pronouns on the audition forms. I had to have a talk with one of the professors here because I was in pedagogy with her and it was like "I cannot listen to you talk about my voice as if it's a woman's voice any longer than you already have," and I sent an email to most of the voice faculty saying that we should stop doing this. I also sent it to the music therapy person and the education pedagogy professor too, but... I don't know. Something else I wanted to touch on was the amount of work that I've had to do as a student that shouldn't have been placed upon me. Like [academic professor's] always like "oh don't bite off more than you can chew, don't feel pressured to do it", but if I don't do it, no one else will.

[Gwen] Yes!

[Delta] Like, if I hadn't asked the building director to put tampon boxes in the men's bathroom, no one would have. And so every time I had my period, I would have to awkwardly carry gross stuff out of the stall, or I would have to walk all the way to the gender-neutral bathrooms that only exist in one location, which is... granted, good that they exist in general, thank you to the professor who made that happen. 
[Gwen] Right.

[Delta] Like. I had to address the voice faculty about that. I talked to them about dress codes-- I think I'm pretty much the reason that the dress codes started to change because we started to be in a situation where you can't just say "men and women" in choir, so that changed.

[Redacted]

[laughter]

[Delta] But yeah it's silly stuff like that! Literally as long as I've been here I've been trying to get the choir director to change Men's and Women's choir to not that, and reluctantly... she was going to change, and I think the reason she did it like she did is because she views nonbinary people as like "women-lite".

[Gwen] Yep.

[Delta] Because the only two nonbinary people she knows were assigned female at birth, and can still sing "women's" voice parts or whatever. So she was going to split the women's choir into an auditioned and non-auditioned treble choir, but then keep men's choir because, and I quote, "there's just something special about a group of men singing together." And I have that in writing, and I actually brought it to another professor and said "hey this can't happen". It was this whole ordeal because the director... it was the weekend before I had to register for classes and I had heard nothing about what choirs were going on, so I sent her a message that said "hey, I'm feeling really anxious about this because I have to register for classes on Monday, and I haven't heard anything and because of my class schedule, there's a chance that I' $d$ have to be in chamber choir because A: community choir might not be happening and B: men's and women's choir are the only two other options, so I'm pigeonholed into one choir, so I really need to know what the options are." And it came off as anxious which, naturally, given the fact that I haven't had a lot of choice the past couple of years over what choir to be in. Then she replied "that was rude, you have no idea what we're doing behind the scenes."

And so I just started apologizing hurriedly and I got really upset about it. I sent an email to her apologizing, and she said "I appreciate your apology, you just didn't know and assumed without knowing. We're actually changing it to treble and men's choir." I went to talk to her in person about it and she pretty much said the same things as she did in the email, like "if I was anyone else, that might have cost you your job in the professional world" and I don't really care if it would've.

[Gwen] Basically just threatening you for having said anything. 
[Delta] Yes. Literally after you stop recording, I'll go back and read you these emails because I need you to know how horrendous it was. And I went to [other professor] like can we do anything about this, because I don't want some other closeted trans person to have to be in men's choir just because there's A: not another choir that fits their voice part or B: fits their schedule.

[Gwen] *gestures to self*

[Delta] Literally! There are trans people I know at this university who would want to take a choir but don't want to be in chamber or community, that just want to be in a middle-range choir. Granted, if it fit in their schedule, they would not want to be in the men's choir. And so we went to the dean and he got it changed, which is good. I actually contacted him near the beginning of the semester, because the director was still referring to it as the men's choir and he said "oh it's probably just to clarify things" and I was like "ok whatever, I don't have the willpower to deal with this right now." But in chamber choir this semester, there's a cisgender female that is singing tenor, so I thought maybe things would be a little bit better because I sing alto in the choir, and the director is still saying "and guys doing this and girls doing that" and I said "excuse me, not all of the sopranos and altos are girls" and she apologizes quietly and I thought to myself "we are literally three months into the semester and I've been out to you for two years now."

[Gwen] Yup. It's that complete refusal to participate.

[Delta] Yeah. And literally, like. Ok, he/him pronouns are pretty affirming to me, and when people write about me I prefer that they use they/them because that's the best for me, but one of the main reasons I have he/him pronouns is because I know that a lot of older teachers and such will, if they don't have a binary to default to, will default to she/her and I would literally rather die than be called that, so if they have he/him, they'll at least be getting part of it right, and I'll at least feel not icky.

[Gwen] Yeah!

[Delta] And most days he/him feels fine, some days I'm like "oh I don't like that," but, you know. Better than the other option.

[Gwen] Yeah, it... ugh. That's... that was how it was for my undergrad too. Like, I dropped out of my ed program to not have to sing, because they had a very heavily gendered choir requirement for all ed majors, and I couldn't do it. And I was out, even! And then the immediate year after they did... do you know the show The Wedding Singer?

[Delta] *nods* 
[Gwen] Oh my god, it's.. It's like that program had an obsession- and I'm just talking about me now [laughs]- but it's like that department had an obsession with finding any and all transphobic shows to put on. Because... and then there's the whole Rocky Horror mess.

[Delta] Yeah, it's just.. I think that the musical theater world is better about LGBTQ+ representation, and sure maybe for the sexuality aspect they're a little bit better, which is still iffy, but in terms of trans people, they literally will dress cisgender men up as "supposed to be women"

[Gwen] Cough cough Hairspray

[Delta] Yeah that one and the one that came out a year before, with the red dress- not Kinky Boots because that's specifically about drag, but... God it just.. Oh! Tootsie. That one. Or in the opera world, there is one opera I can think of that's about a trans person called As One, do you know it?

[Gwen] No.

[Delta] Ok. So it's by Laura Kaminsky who's queer, and so it's good because it brings awareness and is really cool and talks about the fluidity of gender. There's two singers that play Hannah before and Hannah after, and Hannah before is sung by a baritone, and Hannah after is sung by a mezzo, and I'm sure you can immediately recognize the problem with that.

[Gwen] The trans female voice doesn't change!

[Delta] Yeah! So I'm like, when's Lucia Lucas going to be able to play Hannah after? Because there are two well-known trans opera singers, Lucia Lucas is one of them and she could not be in it because of that specifically. And you know, [unclear] aside, literally it's a physical problem that trans women's voices don't get higher, or if they do it's only minimally.

[Gwen] Yeah, it's just through either really risky surgery or years of training.

[Delta] Yeah, exactly. And so you have Lucia Lucas still playing Don Giovanni. It blows my mind. But then there's also this weirdly affirming thing for nonbinary and trans men if they don't decide to change their voices, that they can still sing some pants roles. But then they're called pants roles, which is just women playing men, and it's not affirming, but it is, but it isn't. Because the subject material is affirming, but the entire performance of it is just that, a performance. So this whole weird dichotomy of things. You know, I just wanted to get a degree, I didn't want to come out of here with a gender crisis. 


\section{[Laughter]}

[Delta] I think my main point is that to talk about transness in music is to talk about the fact that university students are also having to be social activists, like we can't just be trans people and university students, we also have to be advocates. Because the last thing I want is for anyone to have the same experience that I did at this university. One of the reasons that I will use the men's bathrooms on a regular basis is so it can normalize it for other people, so nonbinary people don't just have to use the bathroom of the gender they were assigned at birth. In fact they shouldn't. They can use either or both, and it shouldn't matter to anyone. I still get freaked out a little bit, but I feel a lot better about it than I did starting out. I think most of the time I get freaked out is if there are men using the urinal, I'll get super weirded out, but I've gotten more comfortable with it. Also, the men's bathrooms don't have mirrors on the outsides of them. What's up with that? Because I wanted to take a selfie in the foyer of the bathroom, as one does, and there wasn't one! And now I have to walk into the foyer of the women's bathroom to do this, why? Or what, do men not need to adjust their tie?

[Gwen] No, because there's no outward expectation of beauty.

[Delta] And really that's just sexist at this point.

\section{[Gwen] Honestly!}

[Delta] But you can only tackle so many issues when you're taking as many classes as I am

[Gwen] Exactly, and you only have 4 years to do it. I mean, that's just the nail on the head, is that when you are a trans student, you have to also be an activist, constantly, especially within the music world.

[Delta] And you have to advocate for yourself, because not once has another person corrected a teacher's pronouns for me.

[Gwen] Yeah.

[Delta] Saying that out loud was really weird, but I was thinking about every single time-- and sometimes people will be like "oh well we didn't know if you wanted us to"!

[Gwen] What do you mean? 
[Delta] Yeah exactly, like what do you mean you didn't know? Apparently people have done it when I'm not there, and my roommate will correct other people's pronouns in front of me, but we don't have any classes together. But that's the worst part, having to interrupt in the middle of class and-- the two times I've done it in choir have just been... they've created trauma for me because I feel really embarrassed afterwards. And-- I'm getting some neuropsychological testing done, so it's really hard for me to do that and feel comfortable, because that involves not masking, but if I'm masking the rest of the time, I just get freaked out by it. Like I asked a classmate like five times after "was I rude? I feel like that was rude. Everyone was staring at me. Why is everyone staring at me." Or I'll have a stuffed animal with me because I get nervous about choir, and I worry "why is everyone staring at me?" Well it's because I have a stuffed animal and I'm sitting rocking in my chair. All of that. Like is that not a concern? Why isn't that normalized?

[Gwen] Because you're having to advocate for yourself constantly.

[Delta] Whole other issue, but yeah. It's just... really tiring. Because as much as [academic professor] says "take care of yourself, take care of yourself, it's not your responsibility", at the same time I always go back to the thought that if I don't do it, no one will. Like I know I can't do everything, but I feel like I need to be, and I shouldn't have that pressure, but... nothing's going to happen if I don't.

[Gwen] Yeah! Exactly, that's something I see echoed across a lot of trans peoples' experiences, is just this... I don't want to call it a "hero complex" because that's not correct. It's not like we're choosing... I'd have to think about it and chew on what to call it, but... we have to advocate for ourselves, otherwise we will suffer.

[Delta] Yeah, I mean I think it's a survival instinct honestly. Or like, it was right before COVID and-- the only good thing to come out of COVID is that I haven't had to deal with this issue again-- we had to stay in a hotel for choir, and the director was picking rooms. So I talked to her and asked what we were going to do about my room, and she said "ok I'll post a room and see if you're ok with it." She put me with two random girls, and I said "there are only two people in this choir, two girls that I trust myself to be around during a gender crisis, and if you don't put me with them, then you'll put me with the guys." So she immediately put me with the girls. If she hadn't, like if neither of them had been there, then she would have just had to deal with it because I deserve to be in a room that I feel comfortable with the people in.

[Gwen] Right! Like that's my experience too. Because I was in a touring ensemble in college, and I had the benefit of being a binary trans person that they could just switch my roomings, but it's-- I have nonbinary friends who were in that same program who absolutely experienced that, and it was just this incredibly dysphoric experience for them. And so unnecessarily too! 
[Delta] Or, my favorite thing is that this semester I finally submitted the preferred name form to the university, because I haven't legally changed my name yet, and the only thing they changed was my degree works, which no one sees except my advisor.

[Gwen] Yup.

[Delta] So my email still pops up as my legal name, on ecampus when we have to do discussion boards and be in class, it's still my legal name. And I wonder what was the point of the form if they're going to do jack shit about it.

[Gwen] Yes! I'm in that exact same situation, like the form does nothing! The form does absolutely jack shit! And I mean, for me there's a lot of negativity connoted with both first and last name for me, and so it is inescapable. And you spoke before to having to correct professors in class-- it's always that first day when you're in person where you have to stay after class and you're just awkwardly holding on to your bookbag straps and you have to ask "well would it be ok if you could not deadname me and cause me massive mental health issues?" And they're like "hmm I'll think about it."

[Delta] "Just maybe, if you really want it". I've started emailing my professors before class, but that won't even stop the head of the acting school. Before I changed my name, there was a girl who has the same name as me, and she actually got married and changed her last name, so now neither of our initials are the same but before we both had the same initials. And people got us mixed up a lot, which is fine, but there was an email this semester- keep in mind we've both been in school for four years, our last semester, I got copied and put into the musical theater seniors list, my full deadname, my email, and it was supposed to be her. So not only did I get deadnamed in front of everyone, because it was my last name, but this guy who's had her as a student for four years did not get her last name and email correct on this list. And I thought "ok first of all that sucks for her because she feels like she doesn't matter." But also I emailed him back-- well first of all I wanted to be like-- well it was this email introducing them to this casting agent and I really wanted to email the professor and say "yeah thank you so much for inviting me to this class, would you mind letting me know the time and place and also changing my name" but I didn't. I said "hey it would be really lovely if you updated your records so that you don't deadname me in front of all my classmates, and I hope this girl has found this email at this point."

[Gwen] "It would be so nice if you could give me just one crumb of actually good human behavior please"

[Delta] It's fine 
[Gwen] "but if you don't want to, if you don't want to put forth that minimal effort that's fine, I'll just go suffer."

[Delta] Yep. Also if one day I happen to meet that casting director in New York, and I have the same last name, he'll be like "oh wasn't this your name?"

[Gwen] Yeah, and now that bridge is burnt!

[Delta] And fifteen of my closest friends just now had to see that again.

[Gwen] Yeah. Yeah!

[Laughter]

[Pause]

[Gwen] I know that we've basically been talking about this the entire time, but how do you feel that your gender impacts your music?

[Delta] I mean, as a vocalist, my body is my instrument, so I had a lot of struggles before I got top surgery over winter break with... because, you have to be out in the open, I would start caving in because it was bad. It actually took a couple of months after surgery for me to undo that, because my body would still react in the same way. Then, for me I actually found a binder that fit me really well that I was able to sing in, so that's nice- not everyone can have that experience or can afford that experience, so that was a plus. By the same token, I think that the journey of loving my voice has transcended gender, because I think a lot of my problems with my voice didn't actually have to do with my gender. I think before I had top surgery I felt a lot worse about my high range, but that's one of the main reasons I haven't started hormones and I don't really plan to, because I really really like my voice, and I've grown to love it. I think that's a battle that I like to fight, is the idea that a high voice has to be a girl's voice.

[Gwen] Yeah.

[Delta] Plenty of everyone has high voices. And my voice isn't particularly high, I have high notes. Like especially in jazz, I sing a lot lower a lot of the time. So I think, for a while it was a big deal, I also think that the teacher I had at the time tried to make my voice and how it sounded a bigger deal. I don't want to go into too much detail while you're recording, but suffice to say that the teacher I was studying with tried to make a lot more of my vocal struggles about gender than they actually were. I think it stunted a lot of the growth that could've happened my junior 
year, because of that. Because everything was always "oh well this is because you're being dysphoric" not because I'm literally breathing the wrong way.

[Gwen] Yeah. It's just being blinded by that issue, that there is this very physical answer, but they can't see past the fact that you're trans.

[Delta] Yeah, pretty much.

[Gwen] Yeah. God! Echoes of so much of what I've seen.

[Delta] Yeah, and I can't really speak to other instruments or concentrations as what specific gender struggles they experience, but especially for voice and musical theater and opera, where all the roles you sing are binary and it's not common practice except in "gender bent cabarets" to sing stuff outside of the key it's written in. I think if opera and musical theater as a genre want to progress, they have to be willing to transpose roles. Or to actually create trans roles, or cast trans people in the roles that they feel comfortable in, regardless of their voice range. Because right now, it's-- and I think gender-bent cabarets are just kind of terrible because I think that people should... I think that yes, there are certain stories that gender is relevant, and so those roles should be kept in their gender, but by that same token trans people should be able to play those genders, and I think nonbinary people should be able to play whatever genders they feel comfortable in. So if they only feel comfortable in male roles, sure, fine. If they feel comfortable in male, female, and nonbinary presentations, they should be able to be considered for all three and not pigeonhole themselves into one. Which is how I feel- I think I'd feel comfortable playing a role of any gender, and I think that should be fine because gender is fluid, and I feel that my gender specifically is fluid.

[Gwen] Yeah!

[Delta] Why shouldn't I be able to do that?

[Gwen] Yeah and if musical theater wants to progress, if small-c classical music wants to progress, then it has to be willing to grow, and change.

[Delta] Yep. And I think that there has to be a big stink made about cis people playing trans roles, because not only do we not have enough representation, so roles-- even in shows that aren't about their gender that are for trans people, should be able to be trans, or vice versa; roles that aren't specifically cis shouldn't just be assigned to cis people. So roles that aren't specifically cis or trans, whatever. Or if a role doesn't have anything to do with their gender, whatever. But I don't know, it's just this whole thing. 
[Gwen] Like Eddie Redmayne playing Lili Elbe.

[Delta] Hmm?

[Gwen] Eddie Redmayne as Lili Elbe.

[Delta] I'm sorry, I don't get the reference.

[Gwen] Oh! Do you remember the movie The Danish Girl that came out a few years ago?

[Delta] No, I lived under a rock pretty much.

[Gwen] Basically, The Danish Girl is a movie about Lili Elbe, who was one of the first women to receive MtF bottom surgery and they had her played by Eddie Redmayne, so.

[Delta] I see! Yes, this makes more sense, or like Scarlett Johannsen was supposed to play some trans man or whatever. Like, so many people are so quick to justify it, and it makes me sick. And at first it was in the months before I came out when my program announced they were doing Head Over Heels, and I was talking to a nonbinary friend, and I asked "can you explain to me why [I shouldn't play that role]" Hindsight I didn't understand because I identified with that role, but I didn't know why and they said that it was similar but not the same to why white people can't play black roles and I agreed, like sexuality is something that can be fluid and I have mixed feelings about straight people playing gay roles in the first place, but that's more commonplace, and it's not like it's your gender identity. It's different.

[Gwen] Yeah.

[Delta] It's different, in a sense. It makes me so mad when people say "oh well if only gay people can play gay roles, then only straight people can play straight roles" and I'm like

[Gwen] I'm sorry, which of those two has been discriminated against for forever?

[Delta] Exactly! You just want to be oppressed really badly.

[Gwen] And that's exactly it.

[Delta] It was especially a lot of... I've come into a lot of problems with cis gay white men. I have just, in my experiences, had the most problematic said to me and others have had the same experiences. It just makes me mad. 
[Gwen] [Laughter] Yeah, big underline.

[Pause]

[Gwen] I do want to ask, before we end the recording, is there anything that you want to specifically add into the transcript, like anything you want to see put into the project?

[Delta] No, I don't think so. I think I started on all the tangents that I wanted to have. I had a pretty good idea of the things you were going to say before you said them because, you know, same wavelength. Pretty across the board if you're a trans person in music school, you're going to have the same experiences.

[Laughter]

[Delta] Yeah I said everything I wanted to.

[Gwen] Yeah! Well I'm glad. Thank you.

[Delta] I'm thinking about wearing a dress to my senior recital just to fuck with people.

[Laughter]

[Delta] Because for so long they've been like "ah yes, they're going to wear a suit." Like the one day I wore a dress to choir, ooh, people gave me some funny looks that day. They were like "oh I like your outfit" and I'm like "you got a problem with femboys?"

[laughter]

[Delta] Like I don't want to wear a choir dress, but I want to be a pretty femboy, and I'm allowed to do that if I want to.

[Gwen] It's your gender, use it how you need it!

[Delta] Also I will say that someone that is normally pretty good about my pronouns messed them up that day specifically and I just thought "oof, that one hurt a little bit." And I so obviously knew it was because I was in a dress, because not one other day have they messed them up.

[Gwen] Gender doesn't change with the clothes! Well for some people it does but it doesn't. 
I will actually- I have a resources sheet that I will send you after the conclusion of this, but let me timestamp this. The time is 6:02PM, This is 00100431821. This is Gwen Emler, and [REDACTED], and that's all! Thank you.

[Delta] Yeah! Thanks for thinking of me. 


\section{Conclusion}

I began this project by asserting that trans narratives are neglected at large in our modern world of musicology. That sentence was written down well over a year ago at this point, but its roots stretch back generations, truly beyond my own life and that of my respondents. Myself, Alpha, Beta, Gamma, and Delta are all just some of the more recent people involved in the battle for trans recognition, as well as the acceptance of queer Appalachian lives. Above presented are their stories, uninterrupted by my (now) third-party voice. Let us now examine these, disassemble them and see what overlap exists between their constructions.

\section{------Alpha: Silver Linings in Dissonance}

The first respondent, Alpha, spoke exclusively from the standpoint of a classicallytrained performer, discussing their experiences with that world. I noted several broader threads that merged in the heart of their responses: a discomfort with the gendered aspects of the repertoire for their range, a proportional link between their comfort with their gender and their ease on the stage, and the notion that being consonant with and validated in their gender directly connected with their improved musical ability. I must assume that this sense of comfort and safety in performance as a result of improved extrinsic gender perception and intrinsic inception comes as a surprise to some - the idea that feeling loved and safe in one's gender palpably contributes to positive living is as yet a hotly contested issue. However, Mary Gray's Out in the Country has shown that allowing space for one to be one's queer self is deeply healing. As previously discussed, Gray describes the recorded experiences of a drag community in eastern Kentucky. These people, faced with the darkness of the closet, came together to perform their queerness for one another - to see and be seen. While Gray does not speak to these peoples' 
feelings of betterment as a result of these performances, I have to assume that such healing took place - from personal experience, I know that being seen by loving eyes is profound.

As Alpha's community became more accepting and loving of them, their comfort in performance and quality of performance improved. It is important to note they received private lessons as part of their formal education in music. These lessons undoubtedly played a part in their technical skill, certainly_-but voice lessons don't teach the soul. However, as Alpha became more aware of their gender identity and more confident in expressing it, the texts present within their repertoire became increasingly dissonant with their lived experience. I make no specific reference to any one piece simply because a textual analysis of a Romantic Lied or other similar genre is far beyond the scope of this thesis, but surely a heavily-gendered piece of classical soprano music cannot be far from mind. Indeed it is the genericism of these lyrics that is at fault - the fact of the matter is that the repertoire is so saturated by these pieces that ungendered soprano music is the exception that proves the rule, so to speak. So Alpha, being a non-binary soprano, is absolutely inundated with lyrics espousing a (heterosexual, cisgender) womanly perspective. With performance being inexorable from body and mind, singing from the point of view of a woman when one simply isn't one is damaging.

Part and parcel of performance is how the performer is dressed which, as seen in Alpha's transcript, is a point of note. Though dealt with more directly in Gamma's transcript, Alpha discusses their relationship with performance clothing and their gender. There is more often than not a prescribed dress code for performances, which is often a point of friction between trans students and staff. These codes are almost always built along the false gender binary: tuxedos for men and floor-length outfits with arms covered for women. At best these are defended as a notion of removing a distractor from a performance, allowing the music to exist unfettered, and 
performers are allowed to wear whichever of the two, or mix those elements that are the most consonant. At worst, however, these are rigidly prescribed uniforms, to be executed irreverent of identity. Thankfully, Alpha's experiences were more toward the former than the latter, however the de facto societal pressures at play still created an environment of prescription;

[A]: Yeah. And it's nice because I felt like when I was in undergrad I always felt like I had to wear a dress or a top and a skirt to perform, because that was 'fancy', but now that I'm more comfortable in my gender expression, I'll wear a men's dress shirt and khakis because that's just what I want to wear that day.

Whether these prescriptions arise from regulatory or societal pressures, one is still expected, sometimes commanded to conform. Though a step outside of this work's scope, it still bears stating that this experience of pressure to dress to code is exceptionally damaging for trans children. Honeyed praises of "oh how handsome" and "you should always dress like this" poison the fabric. They make sleeves into barbs, shoes into tripwire, until everything is so explicitly gendered that it's all one can do to just wear a hoodie and baggy straight-leg jeans. Clothing is self-expression-one ought no more claim to prescribe a style of clothing than any other means of speech.

I linger here discussing the damaging effects of cis-normative repertoire to underscore its importance and to communicate a truth: pain can come from something as seemingly innocuous as clothing or the songs that one sings. It is in examining these aspects via Alpha's transcripts, indeed all four of my respondents, that I hope to impart this truth and help others to see the breadth of the trans experience. That said, there are certainly positive aspects of being a trans musician; there are elements of our identity which make the music we create unique. I posit that Alpha's musical ability was enhanced by their being trans, in that their ability to wholly inhabit a persona for their performances is deepened and enriched by their experiences as a trans non- 
binary person. The dissonance between assigned and known gender often weighs heavily on the shoulders of trans performers who, due simply to a fluke of their developing throats, are locked into a world of prescribed dispositions. Very quickly, the trans performer develops a method of distancing themselves from their performance as a means of self-preservation, and Alpha is no different: “...every time I perform I'm a character. Underneath the character I am me, but I'm always a different character in every song that I sing." This character mask serves a dual purpose. It shields the self and enhances the emotional gravitas of the performance. By inhabiting a version of the self which aligns with the lyrics of the piece, not only is the musician's true self unscathed by what amounts to self-misgendering, but this briefly-inhabited self then feels a deeper resonance with the piece, thus changing the quality of the music.

Essentially, this embodied character is able to have a personal connection with the lyrics, which enables depth and meaning in a performance unlike what would be seen in a performer with otherwise no emotional connection to the piece. Though this is certainly a "silver lining" situation, it still evinces a uniquity of trans music making: depth.

\section{-----Beta: Transness in Sacred Spaces}

Respondent Beta is a performing member of his congregation, having sung with his church choir for eight years at the time of this writing. His transcript is unique within this project in several ways: save those from cited authors, his is the only male perspective in this entire project, he is the only respondent that has received no formal classical training, and he is the only participant whose entire musical career has existed entirely within the amateur realm. ${ }^{24}$ Because of this, I feel it important to state that neither his nor any one of my respondents' transcripts can be taken as indices of their respective genders. That aside, Beta offers a novel and sadly rare

\footnotetext{
${ }^{24}$ If it isn't obvious, I don't mean amateur in any condescending sense of the word.
} 
perspective for this work: that of a trans person accepted and loved in the church they grew up in.

Beta discussed at length his experiences with his fellow choir members and his pastor, detailing their embrace at his coming out and their own queerness. His discussion of coming out, being so anxious and afraid of their refusal that he simply left, but then being asked to come back and discuss his perspective with the congregation in a space of love, is profoundly moving. He said it best:

[I was] so worried about them not accepting me that I quit choir for a while. Quit going to church. But then my pastor reached out, who is a lesbian, and she wanted me to give a sermon on being transgender and such for the whole church to get a better understanding of who I am (Most people in my church are between the ages of 50-90 so they aren't really familiar with transgender) so I did. And I had so many older people correcting themselves on my pronouns and offering me comfort and their support. It was great.

I feel it important to note how surprised I was to learn this. It was my personal experience, as is with many other queer people, that church could never be depended on to be an accepting place, let alone one so inviting. That Beta's pastor extended a hand to him and made space for him to speak his truth to an older congregation is deeply healing. Beta also speaks of another choir member, another queer man, who "took me under his wing and taught me how to sing again". This language is both factual and metaphorical. Trans people, especially those born without testosterone, often have to start over again when learning how to sing, a fact which turns many away from either pursuing transition or performing at all. Furthermore, being "taught how to sing again" is such a gorgeous phrase metaphorically_it communicates so much of the experience of coming out and finding one's voice, finding how to speak and how to share who one is. That this tutelage occurred for Beta is, again, healing. 
Beta's relationship between music and gender is almost purely positive, a fact doubtless due in no small part to his community's acceptance. His position is unfettered and concise; ...before I realized who I was, my music I'd perform would be really sad because I was sad. However, now that I know my gender and am proud, my music is much more soulful and confident and happy.

Beta's transcript, though short, has an uncanny way of addressing with precision the concepts espoused herein. From a unity of presented and felt gender comes an enriched understanding of music, as seen in Alpha's transcript. This is indeed the most robust connection between the four transcripts - that consonance in gender enables a deeper musical ability in trans musicians.

It is also useful to view Beta's involvement with the church from a metronormative perspective. His church, without disclosing too much information, is on the Ohio side of the valley, and is in one of the state's more rural locales. To the urban-centric eye, his acceptance in a rural church makes no sense-rural equates to discriminatory, whereas urban equates to acceptance. Certainly this must be proven by works the likes of which I've cited here: Mary Bird's experiences in Leitchfield, Kentucky as relayed by Mary Gray, wherein Bird fights against local government and clergy alike, and the rural dismissal of embodied queer sexuality as relayed in Thomas-Reid's "A Pedagogy of the Flesh." But these stories, while indicative of discrimination, prove the opposite at the same time - that there are people in rural spaces that love queer people and that there are individuals working their fingers to the bone to make spaces safe for us. Mary Bird, in her golden years, fought tooth and nail to claim space for an educational seminar; Thomas-Reid preserved on ink and paper the stories of his gay forebears in spite of his family's attempts at smothering them. While Beta's story is certainly exceptional to some degree, that does not in the slightest mean that discrimination is the rule in rural 
Appalachia. There are spaces where we are loved, where we can learn to sing again. We just have to find them and we have to learn how to help those spaces grow.

------Gamma: In the Trenches, Fighting Gender Binarists

There are so many moments in my life that make me say "how did I not know I was queer" and one of them was my obsession with having different music taste than everyone else when I was younger.

Of my four respondents, Gamma gave the longest interview, a fact I feel worth noting because of the sheer immensity of their contemplations on the subject. Gamma, despite receiving none of the questions ahead of time, offered profound ruminations on trans music and musicians, as well as on queerness and music in general. Their responses reflect points that are at the root of this project: that trans musicians are distinct; that we have a unique relationship with music; that gender dysphoria adversely impacts our ability to perform, but in other ways enables a deeper connection; that trans musicians exist in Appalachia. However, their experiences are reflective of the myriad issues that face trans musicians, with their description of discrimination from their faculty and administration to the end that they discarded their performance major. Gamma's is a reflection of what happens when we do not have empathetic faculty, when those in power are closed to true change, but who nonetheless enjoy the public relations value of espousing a performance of change.

Gamma's relationship with music has evolved alongside of themselves. From their childhood days at the elbow of their grandmother to their new compositions of the present, music has been interwoven with Gamma's life at all points. At the front of our conversation, Gamma discussed a notion doubtlessly familiar to most musicians - that of using ensembles to make friends. This community building as centered around the ensemble is, for many musicians, a bulwark against the crashing sea of social interaction, not least for queer musicians. Ensembles 
can often be the only place for an awkward teenage queer musician to make friends. Where social clubs and classroom bullies subjugate, the band room doors resist. Though different at points, elements of this notion of built queer community are reflected in Mary Gray's work, specifically with her aforementioned ethnography of the Springhaven, Kentucky Wal-Mart drag scene. I cannot pretend for a second, however, that musical ensembles across the nation, especially those in high schools, are devoid of discrimination. What I argue, however, is that they often foster these communities. Contrary to this notion, however, is Gamma's experience with their college's choral ensemble, put here in its entirety:

[Gamma] My sophomore year we went to ACDA, which is the American Choral Directors Association, conference, which is where they do a big honors collegiate choir, and one year the whole chamber choir from [UNIVERSITY] went, and while we were there, our choir director sat in on this lecture about inclusivity in choir, about specifically gender variance in choir. I remember he came back to us with this big inspired speech about how he was going to change his dress code policies and the language he used to refer to voice parts and things like that. And then he never did. So it was still, when I went back to choir, I was still expected to wear a floor-length dress with $3 / 4$ " sleeves or longer, all the things you have to adhere to in concert black. When he was talking about having a third option or getting rid of the options altogether and saying "Wear black, make sure it covers these parts so that we look uniform". But nothing changed and he stayed very binary, you wear a suit or you wear a dress, you perform femininity or you perform masculinity. He never bothered to change the language around referring to voice parts, which I think is huge for a lot of ensemble musicians. It's like when you're talking to tenors and basses and say "guys", that's not true, that's not the full truth... I pushed back against it incredibly hard especially because I didn't want to out myself to him, but I pushed back against it and I said "Hey you said you were gonna do all these things, and if you're not then I'm not going to do choir next semester, and I'm going to take a semester off from it and see if you've changed your mind when I come back. And that semester was hell because of that professor. He was the head 
of our department at that point, he docked my jury score and cited that I hadn't been active in the department, even though I was in every ensemble that wasn't choir and you could've checked my grades, I had A's in every music course I was taking.

[Gwen] So he just out and out went out of his way to cause you harm?

[Gamma] To fuck me over. And what he did was I was half a point away from making the score I needed in order to do a recital so that I could graduate with a music degree. And he kept me at that half a point away, essentially saying "You're either staying another semester or you're doing an extra jury because I don't like you, because I don't like you questioning my teaching methods. So that same semester I dropped my music major and became a music minor, because it wasn't worth it at all. It's not like- and I know that he would've been way more sympathetic to the shit I had to say if I said "hey I'm nonbinary, the reason I want you choir to be more inclusive is for me" I think he would've been more sensitive to that, but I shouldn't have to fucking do that, I shouldn't have to beg a choir director to let me wear what I want to a performance. And I shouldn't have to bring up my transcript to get a jury score reflective of the amount of work I've put in.

This is discrimination in plain terms. When Gamma called on their director to stay true to their word, not only did he balk at the notion, he shot back in full force, effectively forcing Gamma out of the department. Of course, naysayers may look at this event and make some milquetoast assertion that "Gamma should've stayed and made a fuss," "Gamma probably just didn't deserve that half-point," or some other contrivance fashioned of status quo maintenance and side-eyed transphobia. The fact of the matter is that Gamma reminded their director of his own declaration of change and he turned around and bricked them out of their hard-earned degree. The pedanticism of preventing someone from completing a degree by one half of a point in a field of study defined by subjective, artistic interpretation of material is nothing short of hateful, and that it comes from someone in a senior position of power is all the more pathetic. To those that would say that it was Gamma's obligation to make a difference, I point to the end of the quote: "I 
shouldn't have to fucking [out myself], I shouldn't have to beg a choir director to let me wear what I want to a performance." It is not trans people's jobs to out ourselves, to expose our hearts to the spear and our backs to the lash, just to affect change; we aren't Christ. We are human beings with living, breathing goals, not some perversion of martyrs to be used as fodder for social change.

Gamma also explains what queerness in media, in music, looks like to them. They speak at length about using music to find themselves and to connecting uniqueness in taste to queerness in identity. They approach this through a conversation about the queer coding present in the limited songs that their parents allowed them to listen to as a child:

[Gamma] A lot of [queer coding] is characters who feel inexplicably different, they maybe have some big secret that they could never share with the world, they feel like they don't quite gel with other people around them, which was always my experience that I've attributed to about a hundred thousand different things in my life.

[laughter]

But I think a big essential one is queerness, and I think that my queerness in part led to me not fitting in with people my age, and an extension of that was setting myself apart by listening to different music or watching different shows or reading different things. I think it was all- I don't even think it was necessarily performative, because I don't think that I cared enough about what other people thought of me to perform for them. I think that it was really just- I wanted to find things that were unique and I wanted to be an individual.

[Gwen] You found kinship in that difference.

[Gamma] Yeah, totally, I think that that all important sense of individuality is pretty central to being a queer person, where you feel misunderstood and like nothing can possibly get you. ${ }^{25}$

\footnotetext{
${ }^{25}$ Here meaning understand, connect, or relate.
} 
That sense of difference (as Thomas-Reid would say, [kwar]ness) also ties into the limited range of music available to them in their discussion of the formulaic movies made for Disney's television channel. Specifically, they make reference to the quality of representation (or lack thereof) of fat people in those movies and how they internalized those characters' roles in their own experience, stating that "being a fat person you need a lot of redeeming qualities. And some of the biggest representation that fat people get is as characters in the Disney Channel Original Movie who are quiet for the first three-quarters of the movie and then at the end they sing a big solo.” In a few sentences Gamma relates the damage that one-note representation of minority identifiers can have in popular media. I draw specific attention to one line that strikes at the center of the notion of queerness felt in music choice:

I was also, from the ages of 12 to about 15 , really (and this is so queer coded) I was really obsessed with music that nobody else had heard of, and in my small town that's not hard to achieve, because even then nobody had heard of Fall Out Boy, but I wanted to go deeper than that, I wanted to go a level, two levels removed from music anybody had heard of.

By their own recognition, this act of seeking uniqueness in their music is connected to their burgeoning queer identity. Gamma used unique, relatively uncommon music to furnish their queer identity.

Gamma also spent time in their teenage years as a gigging performer, operating mainly in central West Virginia, an experience which they state had a nurturing effect in their distancing from their given identity at birth. This growing distance between Gamma and their given identity, particularly their deadname, occurred alongside and indeed as a result of their gigging. In searching for consonance in identity via stage names, Gamma was able to test identifiers, effectively making their performances a laboratory of sorts. In their words: 
....all of the music I chose was really sad because I was really sad. ...but I always introduced myself as a different name. It wasn't always my middle name (it often was), but I would just pick different names to introduce myself as. Like I was playing a character, I was trying things on, and because I knew it would physically hurt me to introduce myself as my first name. I asked people not to use it as much as possible, and to just try to refer to me by pointing.

This is proof of a trans person using performance-music — to explore and experiment with their gender in a way that minimizes consequence without sacrificing benefit. Contrary to this, and indeed likely contributory to it, is Gamma's relationship with femininity. Immediately after they relayed the above material, they addressed how they performed their gender in their youth. Gamma discusses how they keyed deeply into feminine presentation as a way of apologizing or making up for their weight, so to speak.

[Gamma] I loved dresses and pink from the time I was a little baby, and you know skipping the emo phase, that was pretty much my whole thing, and I didn't have the personality for it, I wasn't particularly bubbly. I was awkward and funny sometimes and loud, but appearance-wise I felt like there was a lot to compensate for. I think I was mostly thinking about my body when I was younger, but I realize now that I was compensating for a lot of things.

[Gwen] And it just manifested.

[Gamma] Mhmm, and was like "if I can look as feminine as possible, then I can compete", so to speak, "with the ugliest thin woman here". It was all about getting to a point where people would listen to what I had to say or people would see me and recognize me and know who I was, know that I was 'girl' by looking at me. I thought people couldn't tell what my gender was if I wasn't wearing a dress and makeup and had long hair. Then, in my junior and senior year, I started identifying as a lesbian. I cut my hair really short, I still wore a lot of dresses and makeup, but I thought that me cutting my hair short was really liberating. Having an identifier like that at such a young age is really powerful. It added 
this new aspect to my character, where I was able to be like "yes I am lesbian, that is me". And that's not me, that's who I thought I was at the time and I think that's valid.

This anxiety around their gender presentation from such a young age, I believe, laid the foundation for their later departure from clear and exclusive femininity. It is important to examine this progression, then, because it is reflective of what relationships trans musicians have with their music. That Gamma used their gigs as a way of exploring their gender identity is communicative of the broader implications of what it means to be a trans musician.

Gamma is one of two respondents who share a strong focus on composition. In their discussion of this aspect of their relationship with music, they express their desire to create music that is specifically queer. In talking about queer sound, they referred to elements like the "weird growly-electronic sound that's taking over a lot of queer music" and emphasized feeling more than specific content. Gamma stated that the subject matter is more important than the genre, I write a lot about mental illness, I write love songs that are written to feel queer. They're not necessarily like the She by Jodie brand of sounding queer, where it's just like same-sex feeling, but something that kind of describes the messiness and the personal conflicts in falling in love. I like music that's anticapitalist, is stuff that I write, music about the great journey of life. You know, cheesy shit like that.

Certainly Gamma's thoughts on the sound queer music are their own, are subjective, and are not broadly applicable. However, that they address queer music as an entity, something tangible, underscores my point that there is a unique quality to trans music, and that trans musicians affect that trans music. Despite Gamma's conflicts with their music department, they are still performing a modified form of a senior recital—in this instance, an album of sorts. They describe it as: 
.... lot of weird electronic sounds and weird acoustic sounds and a lot of my voice layered on top of itself over and over again. Because I... I think that I can.. I'm learning I can do whatever I want, like gender can be whatever I want it to be, my music can be whatever I want it to be in relation to my gender and I could keep singing queen of the night, I could revive Gretchen Aum Spinrager which I was going to sing for my recital, I could bring her back but I don't want to. I'm not interested in that anymore. And it's exciting and new and also altogether scary, because I am sure lots of other trans musicians have experienced this where it's like: if I- am I just going to be the world's greatest boy soprano?

I end this quote of their transcript on an important question that they pose, one which faces many classically trained trans musicians: if I stay in the field, do I just become this almost sideshow anomaly? Do they become, as they say, “the world's greatest boy soprano?" Or, in the unspoken alternative, do I stay closeted for my entire career? These are the two options for classically trained trans musicians: we can either sing in silence, or we can be forever marked by our transness through the slamming of so many unknown doors and and our relegation to being a spectacle of a "man with a woman's voice" or vice versa.

I asked all four of my respondents if they had anything that they wanted to add to their transcripts. Gamma was the only one who did, and their statement had a powerful effect. I quote their statement here in its entirety:

Queer musicians deserve more space in classical music, but I don't want every queer musician to feel like it's their responsibility to make that space for themselves. I tried it, and it sucked. And I've discovered that what's better for me, at least, is doing something different. And I think it can be really scary because classical music is such a harsh reality, such a harsh venue, that it can be really really scary to imagine yourself venturing off from that. But it's so much better than staying within a, a system of art that was built to systematically oppress people. 
Cause classical music is beautiful and has so much value, but also is so deeply flawed in so many ways, that I don't think that you should be afraid to do something that isn't it. And it might be a lot better for you not to. And I don't want to just say "fuck classical music, give up on it!" because that's not everybody's truth, that's my truth. And I still love it, and I'm still going to analyze symphonies for fun, but when it comes to performing, if itif the space isn't there for you, it's not your job always to make it. It just isn't there sometimes, and you aren't letting down the future of queer classical music. You are preserving yourself, and preserving your love of music, which I think is hugely important, because it's really easy to hate music sometimes, it's easy to hate music when you're a cis heterosexual person who's studying music, and it's especially difficult when you're being forced to sing texts that don't make sense to you and when you're being called things you don't want to be called and when you're being asked to dress a way that doesn't feel right to you. So it's- yeah, it- it could be worth it, but also don't be afraid of it not being worth it. I was really afraid of it not being worth it, and it wasn't worth it and I was right.

Gamma's statement strikes directly at the heart of being trans and of being queer in the classical music world. Not only that world, but in the social environment writ large — it is absolutely not the job of oppressed peoples to put themselves through the suffering required to make their own space. That labor is exhausting, destructive, and it ought to be borne by those in control of these spaces. I spare my own words on this in favor of Gamma's, whose statement is unequivocal.

\section{------Delta: Locating the Self in Creation}

...the journey of loving my voice has transcended gender, because a lot of my problems with my voice didn't actually have to do with my gender.

Though the goal of finding, hearing, and listening to trans music is at the heart of this project, I have yet to provide an example of what trans music truly is, but we now turn to respondent Delta. They, though younger than the other respondents, are the only one to have a commercially published album with an extant label. In their transcript, they presented a 
discussion of the motivations behind each of their tracks and they present a clear example of what trans music sounds like in Appalachia. In addition, Delta offered perspective on the elements of each song and how they came to impact the album at large. The bittersweet relationship between Delta and their myriad traumas offer not only a perspective of how trauma can affect music, but also a window onto how suffering is typical of the trans experience. Counter and compliment to this are the lighter tracks of their album, one of which was written with intent to be a "love [song] that's explicitly queer." Their album contains many qualities that one can discern as being particularly trans; perspectives of gender identity, experiences around transition, discussion of pain as related to transness, and "queering" elements of instrumentation and scoring. Additionally, Delta offers reflections on what it means to be a trans student in academic spaces, namely the fact that they often have to become strong self-advocates. It is on the lattermost of these points that I will reflect upon first.

Trans people frequently find ourselves at the head of socio-political movementsperhaps this a quality that we inherited from the late Marsha P. Johnson. Wherever the origin may be, Delta's time spent fighting the good fight falls in line with that legacy. Though they hadn't come out as trans until they were halfway through their Bachelor's degree, Delta has still come to be something of a shaker in their community. By the pressure they applied and the voices alongside them, they have managed to affect an impressive change in their department: they established gender-undesignated restrooms, ensured that the remaining binary restrooms are equally equipped, and pushed to remove binary labels and treatment from and by choral ensembles. These are grand systemic changes that Delta is affecting and are worth our praise. However, as shown by Gamma's case with their interactions with their discriminatory director, by Alpha's grappling with clothing restrictions and heavily gendered repertoire, and Beta's 
education an entire congregation, we shouldn't have to be the sole source of education source and the single voice of change for cis people. Alpha, Beta, Gamma, and Delta each have a right to live their lives without having to enter into the combat of changing someone's perception, nor should they have to suffer from discriminatory practices until they are changed. Put simply, the fact that a trans person is affected by discriminatory practices does not mean that they are obligated to make themselves vulnerable and susceptible as the sole agents of change.

Respondent Delta's album is, in their own words, their "opening statement, like the opening prayer of a church service... "here's the struggles and joys that I've found of being queer, here are the prayers that I have for the future'." At its foundation, their album is a piece conceived in queerness, given its express intent to share what it means to be Delta, to be a trans musician, with its listener. To be Delta, indeed to be trans, or to be queer, is an act of protest. To keep existing in a world that as yet still provides moral justification for hate crimes is an act of dissent against the systemic powers that espouse hate and inequity. When Delta outlines their experiences with discrimination, they are thus filling in part of the picture that is queerness. They begin by addressing a common issue: casting discrimination. Behind the guise of subjectivity and aspirations to the perfect cast or higher consumer satisfaction, casting directors shut out performers who share minority statuses with the character in favor of those who don't. One need look no further than their television set to find myriad examples of miscast roles. In the transcript, I reference the 2015 film The Danish Girl, which stars cis man Eddie Redmayne as the titular Lile Elbe, one of first women to undergo genital reconstruction surgery. The perennial argument for miscasting like this usually involves some assertion that no actors who share minority status auditioned (which is rebuffed by actors declaring that they auditioned for the role, or by the release of casting directors' guidelines that specifically exclude minority actors). 
This assertion usually meanders to its true motivation: that minority people are less important than cis het white men and should be happy with the crumbs and bit-roles we get to watch. What is shown in Delta's transcript, then, is proof. Proof that actors who share minority statuses with characters audition for and are routinely denied parts. This is discrimination, and it is destructive. Though they don't linger on the subject, it is apparent that this situation caused Delta undue harm - the theme of undue suffering surfaces again in their experiences with faith as related to their gender and sexuality.

As noted in Alpha, Beta, and Gamma's transcripts, trans people often have a complicated relationship with religion that ranges from next to no interaction, as in Alpha's case, the positive and loving community seen in Beta's transcript, to the ambivalence of childhood memories that Gamma communicated. Delta's relationship with the church, however, was expressly negative. Delta was born into the Greek Orthodox tradition, an organization known for emphasizing its historical legacy and tracing its practices to before its schism from what would become the Roman Catholic tradition in the 11th century. More than just being born into it, their grandparents and uncle were directors and a priest, respectively. This undoubtedly deepened the connection between familial love and piety, putting a young Delta into a difficult situation vís-àvís their burgeoning queer identity. Delta explains this through a retelling of an experience with their uncle;

\footnotetext{
...when a couple of my friends started coming out to me, I actually went to my uncle who's a priest, and I said "they're the nicest people ever, how do I deal with that?" and he pretty much said "yeah, you still show them God's love, but I pray my daughters never try to bring a girlfriend home. Because I'd let her in to show I truly love her, but I pray that would never happen."
} 
Besides emphasizing clear double-standards, this scene is an obvious point of damage for Delta. They point to this moment as being something which delayed the realization of their queer identity, and it truly is no surprise — being told by a family member that queer people are undeserving of love or are only worth a trifling performance of passing acceptance made only out of obligation to the Almighty is damaging, to say the least. In direct reply to this, Delta explains their current understanding of the divine and the lengths of its love, rhetorically saying to their uncle that “...'if you're saying God is loving and you're saying I'm made in the image of God, then all of these other things should be true and God will love me because I'm trans."' I linger on Delta's relationship with the divine not for its own sake, but because of how this reflects on their music and connects to the stories of the other three respondents. For example, the tracks of Delta's album are keyed intentionally to match a chord progression with a plagal cadence: "So I start in $\mathrm{C}$ minor, then I continue in $\mathrm{C}$ minor. Then I go to Ab, so the flat six, then in the fourth piece I transition- haha- from $\mathrm{Ab}$ to $\mathrm{G}$, so I move down a half step, and then $\mathrm{G}$ is the 5 in $\mathrm{C}$, and then from $\mathrm{G}$ I go to $\mathrm{F}$, which is the IV, and then one.” Delta's experiences with religion is made apparent not only in subject matter and text, but in the theoretical underpinnings of the music itself. I also would like to make note of their laughter after the word "transition"besides an instance of clever wordplay, communicating transition in music is something that Delta makes a point of, particularly in one specific track;

Then that moves into [song], which is sort of a transitional piece in and of itself, because the first two verses are "I know who I am, but no one else thinks of me that way" and then the third verse is "hey, I'm going to be me, and it doesn't matter, I won't ever be gone" and it's like setting an intention in a way.

Here again we see how being trans shapes and colors the work of trans musicians. 
Famed author and musicologist William Cheng co-authored, alongside Gregory Barz, the collection Queering the Field: Sounding Out Musicology — a text which centers around what it means to study queer music from an ethnomusicological perspective, as well as how being queer colors ethnographers' perspectives. I make mention of it here to reference its introduction, written by Barz, and the explanation of queering contained therein. Barz's definition is that “...'to queer' does not mean to throw out categories, but rather to explore elasticity... [it] also acknowledges the complexity of embracing the existence of two (or more) ways of understanding a given scenario." ${ }^{26}$ Additionally, Barz quotes Cheng's chapter to underscore what the word queer means, stating that “queer isn't just liminality, interstitiality, and performativity. Queer is the bottles thrown, the bodies broken, the flesh and the flame, the strategic rationing and renewal of how many fucks we have left to give." ${ }^{27}$ In the context of Delta's transcript, one can see how elasticity and interstitiality_-between-ness — ring deep in both their music and their self. For example, Delta explains that the first track of their album initially came from a ...moment when I should've known I was gay, but I didn't. There was a vigil that we had in my hometown for the Pulse nightclub victims, and I went with who would later be my girlfriend, and she was leaving for Germany soon after that. So we were driving home from the vigil, and we stopped in front of her house. We both got out of the car and it was pouring rain and we just stood in the rain and hugged, and should have kissed but just hugged for like 30 minutes and I was thinking the whole time "I should kiss her”, “wait I'm straight", "what's going on". It was this whole thing, and then for two months I ignored that because she was in Germany the whole summer.

Queer romantics aside, this scenario that Delta presents portrays an elasticity in selfunderstanding that is not unfamiliar. They describe an internal conflict of sexual identity,

\footnotetext{
${ }^{26}$ Gregory F. Barz, Queering the Field; Sounding Out Ethnomusicology (New York, NY: Oxford University Press, 2020), pg. 15.

${ }^{27}$ Barz, Queering the Field, pg. 26.
} 
centered around an event that occurred, eventually, because of a hate crime. This situation is at once passionate, depressed, anxious, and elated — all of which Delta takes in stride. This situation exists in the in-between of strongly positive and negative, of triumph and despair: the same intersection at which queerness resides. So, then; how does this translate into their music? How does the queering of romance translate into their first track, or any? As shown before, Delta queers the plagal cadence using the keys of the album, but they also do this through their instrumentation and, truthfully, the genre they work in. Delta explains later that

[Delta] ...even though the only thing I took directly from the [Byzantine] chant is at the beginning and the end, I stayed in the chant feel when I was writing the melody so that it would really be juxtaposed with the funk beat, the jazz organ, stuff like that.

[Gwen] Kind of like queering those elements.

[Delta] Oh yeah, exactly.

Admittedly, I provided the phrase "queering elements," but it is still apparent that this was their intent. Delta also talks about their incorporation of tap to both communicate the joy of a queer space about gay clubs, as well as to be adventurous in their own performance abilities. That they performed the tap themselves, despite having no formal training in method, also speaks to some degree of queerness - they departed from the convention of institutional training, bypassing (eventually) societal rigor, to communicate a musical concept that they envisioned. Rather than the concept staying inaccessible yet visible behind a window, Delta broke the glass and took it-this is queer. In their own words: “...that song's all about being free.”

I have not yet mentioned the various discriminatory situations that Delta outlined, save for the above discussion of discriminatory casting. However, their experiences with the faculty of their university are not at all uncommon to me, and are indeed echoed across the transcripts in 
this project. Delta relays several of their experiences of discrimination and hateful interactions, but I focus on one in particular: their altercations with their choral director:

[Delta] as long as I've been here I've been trying to get the choir director to change Men's and Women's choir to not that, and reluctantly... she was going to change, and I think the reason she did it like she did is because she views nonbinary people as like "women-lite". [Gwen] Yep.

[Delta] Because the only two nonbinary people she knows were assigned female at birth, and can still sing "women's" voice parts or whatever. So she was going to split the women's choir into an auditioned and non-auditioned treble choir, but then keep men's choir because, and I quote, “there's just something special about a group of men singing together."... and I actually brought it to another professor and said "hey this can't happen". It was this whole ordeal because the director... it was the weekend before I had to register for classes and I had heard nothing about what choirs were going on, so I sent her a message that said "hey, I'm feeling really anxious about this because I have to register for classes on Monday, and I haven't heard anything and because of my class schedule, there's a chance that I'd have to be in chamber choir because A: community choir might not be happening and B: men's and women's choir are the only two other options, so I'm pigeonholed into one choir, so I really need to know what the options are.” And it came off as anxious which, naturally, given the fact that I haven't had a lot of choice the past couple of years over what choir to be in. Then she replied "that was rude, you have no idea what we're doing behind the scenes." And so I just started apologizing hurriedly and I got really upset about it. I sent an email to her apologizing, and she said "I appreciate your apology, you just didn't know and assumed without knowing. We're actually changing it to treble and men's choir." I went to talk to her in person about it and she pretty much said the same things as she did in the email, like "if I was anyone else, that might have cost you your job in the professional world" and I don't really care if it would've.

[Gwen] Basically just threatening you for having said anything. [Delta] Yes. 
Here there is nothing hidden. A professor of Delta's, after waving off their recommendations for positive change, saw fit to verbally berate them and thus highlighted the precariousness of their position by essentially threatening them with recourse for even suggesting that they do something differently. This kind of treatment apparent in Gamma's experiences with their director as well and, though more distant, Alpha's dysphoria as related to their repertoire as well.

\section{------Now What?}

At present, I'm sitting next to an open window, taking in the coming spring air with an iced coffee. The COVID-19 pandemic that ripped through my home and stole far too many lives is now, by grace, on the retreat; my fiancée and I are set to receive our first vaccine on Saturday. Part of this project has been an encapsulation of the pandemic experience-interviews over video-chat instead of in person, battles with mental health, and the like. As I previously discussed, this was originally meant to be a large-scale project, enough from which I could draw genuine statistics. More than that, though, it was to become an exercise in community building. The national park adage of "leave nothing but footprints, take nothing but pictures" doesn't really apply when one is working with people - invariably, one impacts the community by their presence. Had this project not been slashed, I had hoped it would've led to some great meeting of peoples, networking. Alack and alas. Reflections aside, this project is now reaching its end and, much like Gamma, I’ve got closing thoughts.

My four respondents are just a sliver of the broader population of trans musicians in the Ohio Valley region. I make note of this to underscore that Alpha, Beta, Gamma, and Delta's experiences are just that: their experiences. Broad-brushing minorities is not what this project is about, and I refuse to not tell the reader so directly, so as to dissuade such a reading. Moreover, it 
is deeply important to note that all four of the respondents are white, and I am as well. Thus, this work cannot and should not be taken to be indicative of the Black trans experience, or indeed of any non-white experience. To my limited knowledge, there are as yet no studies comparable in scope to mine that discuss Black lives, a fact that I hope changes in the future.

I feel that it is also essential to note how close I am to this project. As stated in the introduction, I am a white trans woman who is also a lesbian, which inherently shapes my perceptions of my respondents' transcripts in known and unknown ways. For example, I'm deeply aware of the bias I have against cis men en masse, something I came by honestly from the negative actions of a few. Though I cannot pinpoint textual examples of where that bias shows itself, it is important that the reader understand that about me. Further, I'm a middle-class Appalachian communist - facts that also alter the nature of my approach. I volunteer this information for two reasons: to underscore why this work is so important to me, and to disqualify this work from being taken on as some perfect entity. It's not perfect, far from it, but it is the perspective of one trans girl talking to her friends about what it's like being us and making music.

The battle to have trans voices heard in all forums of life is an inherited torch; the flame lit by trans people generations ago burns bright in this project. I can't pretend that what is put down here is even close to the final blows in that battle, but I can hope that it serves to change the minds of some of my fellow musicologists. To that end, I propose these actions-each built from the stuff of Alpha, Beta, Gamma, and Delta's experiences: the advocacy for ungendered repertoire, the championing and safeguarding of the trans people in our lives, and the uprooting of systemic transphobia. 
The uncovering, fostering, and (most importantly) acceptance of ungendered repertoire is fundamental to putting an end to the harm that gendered repertoire does. I charge musicologists to engage with archives in the process of unearthing the ungendered repertoire of ages pastqueer people have always existed, thus our music must too. These works must be brought into the limelight, and we must work to make these works accessible since they do no good simply sitting in archives. Additionally, new, ungendered compositions ought to be the focus of original writing contests - the presence of music by the Old Masters, while undoubtedly beneficial, is no more important than the propagation of new pieces. To the final, most essential point: these works must be accepted and endorsed. It would be extremely easy for the powers that be to simply write these works off as non-canonical, irrelevant, or useless. This is unacceptable. Exisiting of the so-called "accepted canon of works" is no reason for the condemnation of its quality or its importance. This music has the potential to save lives, whether musical or corporeal. Being forced to perform material that is destructive to the performer's mental health is an act of violence; defending someone, a musical comrade, from violence is what we all must do.

Trans people, especially trans children, are exceptionally vulnerable to discrimination. This isn't to say that we're weak, far from it. But the truth is that there are myriad systems at play to mechanically destroy and erase trans lives, and we suffer from those. With that in mind, it is essential that those with the power to protect trans people do so and that they come to the task readily. Yes, that means standing up to discriminating conductors. Yes, that means voting and rallying and being politically active. Yes, that means listening, hearing, and loving. I cannot prescribe exactly what that the reader should do to affect this in the circles of their own life. But treating and loving trans people fairly while doing what you can to protect us is what is important. 
It is no secret that the people who actively rail against trans lives walk around free. Seventy-eight of them work in Charleston, West Virginia, signing off on hate speech and violence against trans student athletes, just like any other measure. ${ }^{28}$ Seven of them live in Charlotte, North Carolina, convincing each other of the fool's notion that a bathroom is gendered. ${ }^{29}$ One of them now currently resides in Pensacola, Florida, his pathetic orange-toned skin wrinkling on the Gulf shore. ${ }^{30}$ These are perpetrators of violence. These are people who condone hate for and the destruction of trans lives. Our vote has the power to oust people like this, and it's essential that a politician's perception of trans people be known in order to gauge their aptness for office. Moreover, one cannot be neutral about whether or not someone deserves to live free. To do so is to side with the negative, with those who would sooner see us bleed out in the streets. I understand that this can come off as harsh perspective. To that, I rebut: without the people who fought for our right to live, neither this paper nor these stories could exist.

I'm left wondering what has changed and what hasn't throughout the duration of this project. I know that some of my respondents are really excited for this to come out, and I am too- but what does it do? Is some politician going to hold up a sheaf of this work and proclaim grand systemic change, metaphorically parting the Red sea and drowning Pharaoh's chariots? Will someone remember this thesis and decide to vote against the continued oppression of trans people, or decide not to insult, assault, murder, erase? More realistically, perhaps an educator or conductor or someone will take in the stories put down here and take thoughtful pause the next time they have the opportunity to interact with a trans person. I cannot know. What I do know is that work like this, representation like this, love like this, is what I needed when I was a kid.

\footnotetext{
${ }^{28}$ Quinn, Ryan, "WV House Passes Ban on Transgender Students," Charleston Gazette-Mail, March 25, 2021.

${ }^{29}$ In reference to the Public Facilities Privacy and Security Act of 2016 in North Carolina.

${ }^{30}$ Phillip, Abby, Thomas Gibbons-Neff, Mike BeBonis, "Trump Announces that he will Ban Transgender People from Serving in the Military," The Washington Post, July 26, 2017.
} 
Maybe now she can go play and make music and be happy, and maybe now someone else like her can too. 


\section{Works Cited}

Barz, Gregory F. Queering the Field; Sounding Out Ethnomusicology. New York: Oxford University Press, 2020.

Girshick, Lori B. Transgender Voices: Beyond Women and Men. University Press of New England, 2008.

Gray, Mary L. Out in the Country: Youth, Media, and Queer Visibility in Rural America. New York: New York University Press, 2009.

Hubbs, Nadine. The Queer Composition of America's Sound. Oakland: University of California Press, 2004.

Phillip, Abby, Thomas Gibbons-Neff, and Mike DeBonis. “Trump Announces That He Will Ban Transgender People from Serving in the Military.” Washington Post, July 26, 2017.

Quinn, Ryan."WV House Passes Ban on Transgender Students Playing on Sports Teams Matching Their Gender Identity.” Charleston Gazette-Mail. March 25, 2021.

Ryerson, Rachael, and editor. Glasby, Hillery,. Storytelling in Queer Appalachia Imagining and Writing the Unspeakable Other. Morgantown: West Virginia University Press, 2020. 
Spencer, Leland G. and Jamie C. Capuzza. Transgender Communication Studies. Lexington Books, 2016. 